\title{
HEWLETT-PACKARD JOURNAL
}

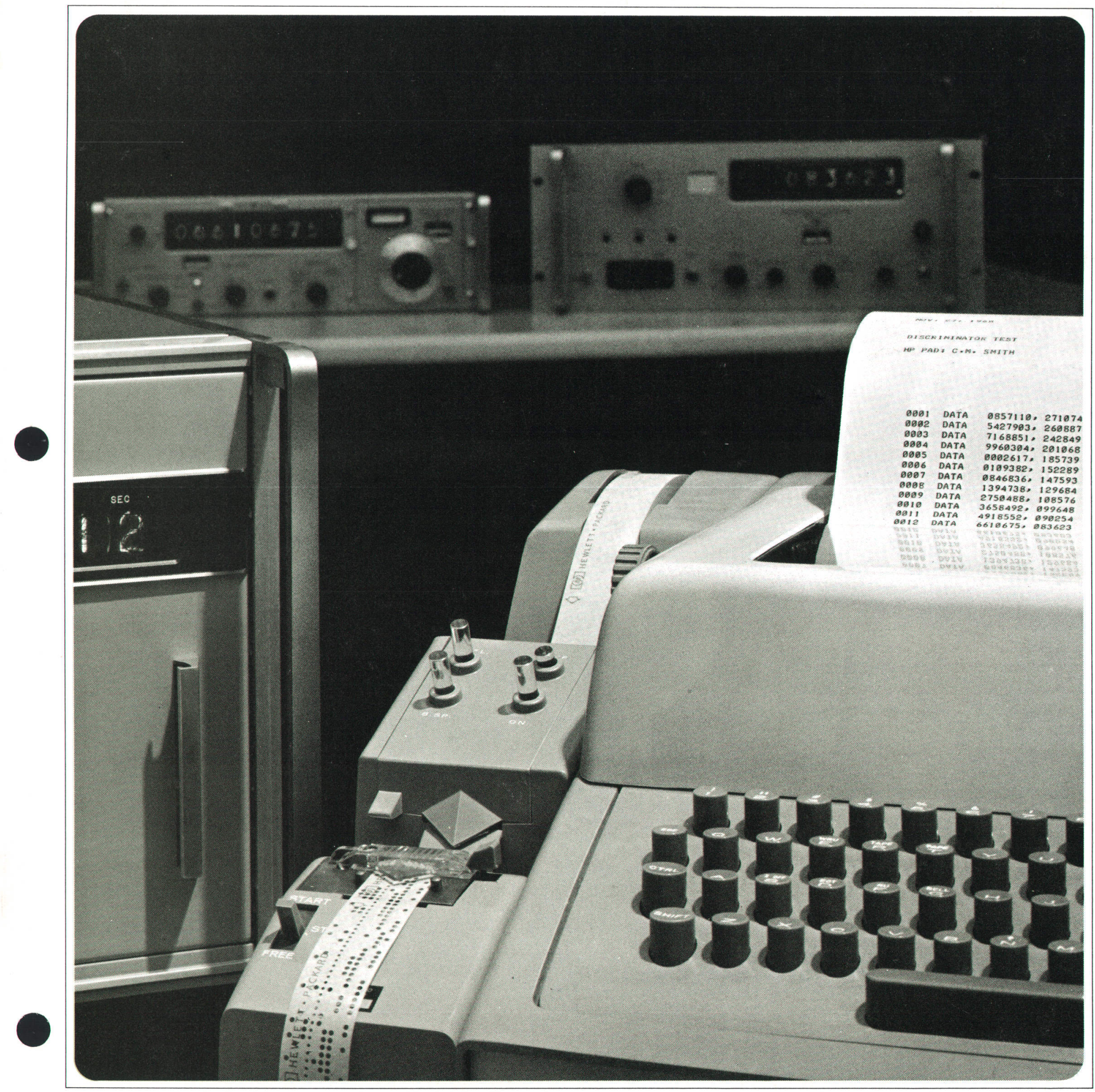

JANUARY 1969 


\title{
Broadband Passive Components for Microwave Network Analysis
}

\author{
It takes more than an advanced network analyzer to make \\ accurate, broadband device-parameter measurements. You \\ can't do it without precision, broadband hardware-things like \\ directional couplers, line stretchers, switches, and transmis- \\ sion lines. It also helps to have everything in one instrument.
}

\section{By Stephen F. Adam, George R. Kirkpatrick, and Richard A. Lyon}

THERE WAS A TIME, not very long ago, when microwave transmission and reflection measurements were nearly always magnitude-only measurements. People were interested in phase, of course, and it would have been most desirable to have a system that could measure magnitude and phase looking into or through any two-port device. But a system that could do this, and do it over very broad frequency ranges, conveniently and accurately, would have been extremely expensive and complex.

At Hewlett-Packard, the key to broadband microwave measurements proved to be a dc-to-12.4-GHz sampling device, developed in 1966.[1] Using the device as a harmonic mixer, a network analyzer system, Model $8410 \mathrm{~A}$, was developed and introduced in 1967. ${ }^{[2]}$ The network analyzer is basically an instrument which measures and displays the complex ratio of two signals. Specifically, it measures the complex reflection and transmission coefficients, or s-parameters, of active and passive devices. ${ }^{[3]}$ These parameters characterize the device completely.

Besides the network analyzer, two other elements are needed to measure network parameters. One is a swept signal source, and the other is a collection of passive components for interfacing the signal source and the network analyzer with the device being tested. Fig. 1 illustrates the three elements and their relationships. The passive components take the signal from the sweep generator, isolate part of it for use as a reference signal, and direct the rest to one of the ports of the device being

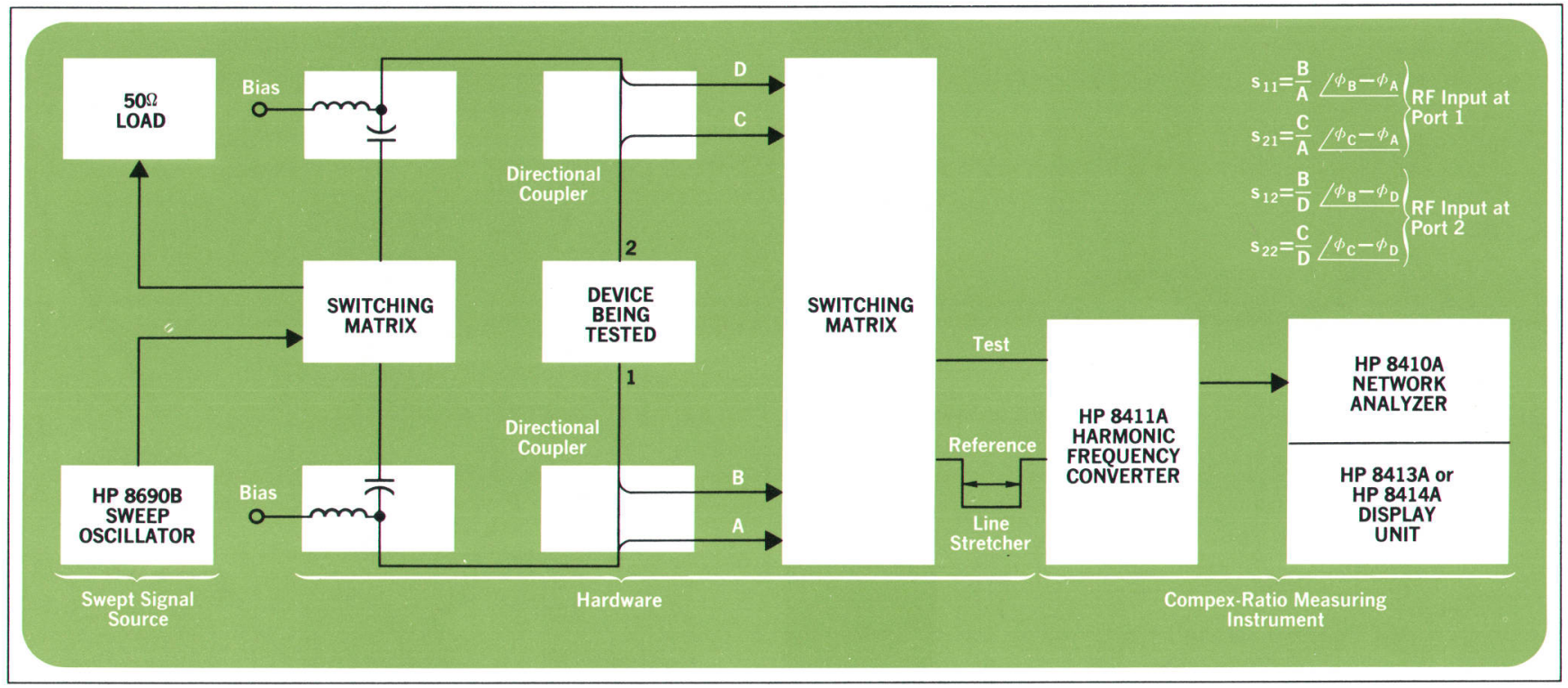

Fig. 1. An automatic, broadband system to measure s-parameters has to have three parts: 1) a swept signal source, 2) a complex-ratio-measuring instrument, in this case the HP 8410A Network Analyzer, and 3) hardware to interface the sweeper and the network analyzer with the device being tested. To maximize the accuracy, bandwidth, and convenience of the system shown, all new hardware had to be developed, including directional couplers, line stretchers, switches, and devices to take the place of flexible cables. 
tested. They then separate the signals entering each port from the signals leaving that or other ports of the device and present all of these signals to the complex-ratiomeasuring instrument, the network analyzer.

Early in the development of the network analyzer system it became apparent that the passive components would largely determine how accurate, convenient, and broadband the system would be. The signal sources were available and, once the sampler was developed, the network analyzer was no longer the limiting factor. But existing directional couplers, switches, line stretchers, and cables were either narrow-band, or had high VSWR's or other problems. Their narrow bandwidths alone meant that many changes of components would be needed to make broadband measurements, and this wasn't a pleasant prospect. Consequently, new components were developed. Among them are high-directivity directional couplers, switches that are highly repeatable, low in VSWR, and versatile, a low-loss, low-VSWR line stretcher, biasing networks, and devices to perform the function of flexible cables.

\section{Two Instruments Have All Necessary Hardware}

To measure the four scattering parameters of a device using separate components, several changes of cabling, couplers, line length, and terminations would be needed. Connecting, disconnecting, and rearranging components would not only eat up time, but would also reduce the accuracy of the measurements. To eliminate the need for changing components, all of the newly developed components that are needed to measure s-parameters have been grouped into two precision transducer instruments (Fig. 2). Model $8745 \mathrm{~A}$ S-Parameter Test Set operates over a

Cover: Model 2547A Coupler, at left, is shown recording the readings of a counter and a digital voltmeter on punched tape for entry into a time-sharing terminal. The data format here is compatible with programs written in the BASIC language. Many other uses of this versatile digital coupler are detailed in the article on page 15.

In this Issue: Broadband Passive Components for Microwave Network Analysis; page 2. Measuring High-Frequency Transistor Parameters; page 11. Printed-Circuit Slide Switches Save Panel Space; page 13. Recording Data for Computer Analysis; page 15.

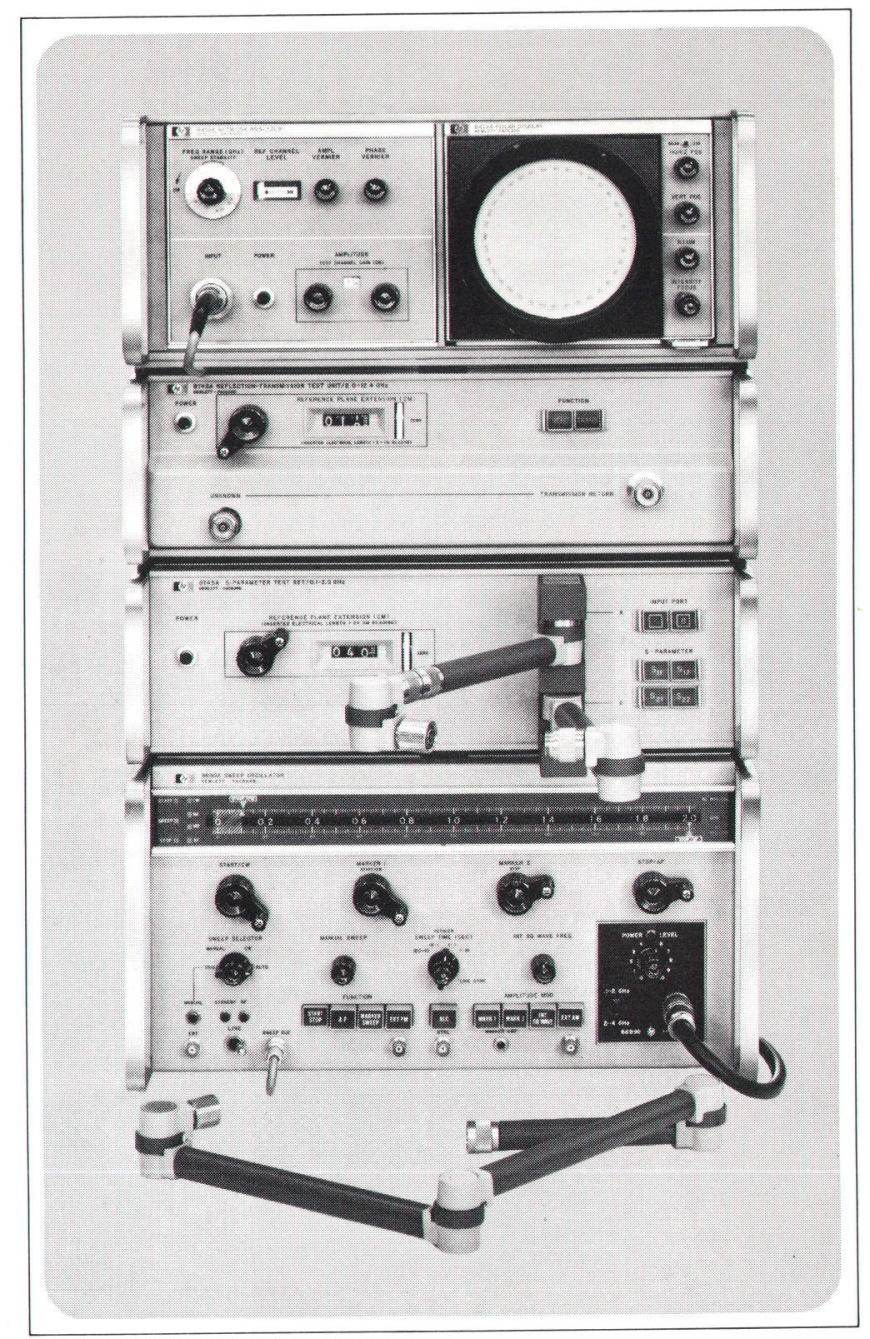

Fig. 2. Model 8745A S-Parameter Test Set (third instrument from top) and Model 8743A Reflection-Transmission Test Unit (second from top) contain the directional couplers, switches, and line stretchers needed for network analysis. Devices to be tested are connected by means of flexible arms which replace inaccurate flexible cables. The network analyzer (top) and sweeper are the other elements of the network analysis system.

frequency range of 0.1 to $2 \mathrm{GHz}$. Its high-frequency counterpart, Model 8743A Reflection-Transmission Test Unit, operates from $2 \mathrm{GHz}$ to $12.4 \mathrm{GHz}$.

Model 8745A S-Parameter Test Set is useful for measurements on microwave hardware, solid-state devices, components, and transistors.* The two-port device under test is connected once to the Test Set, and the parameters to be measured and the reference port are selected simply by pushing buttons.

Fig. 3 shows the internal arrangement of the S-Parameter Test Set. The two directional couplers in the Test Set are mounted so that they can move slightly in any

* See article, p. 11, on transistor measurements. 


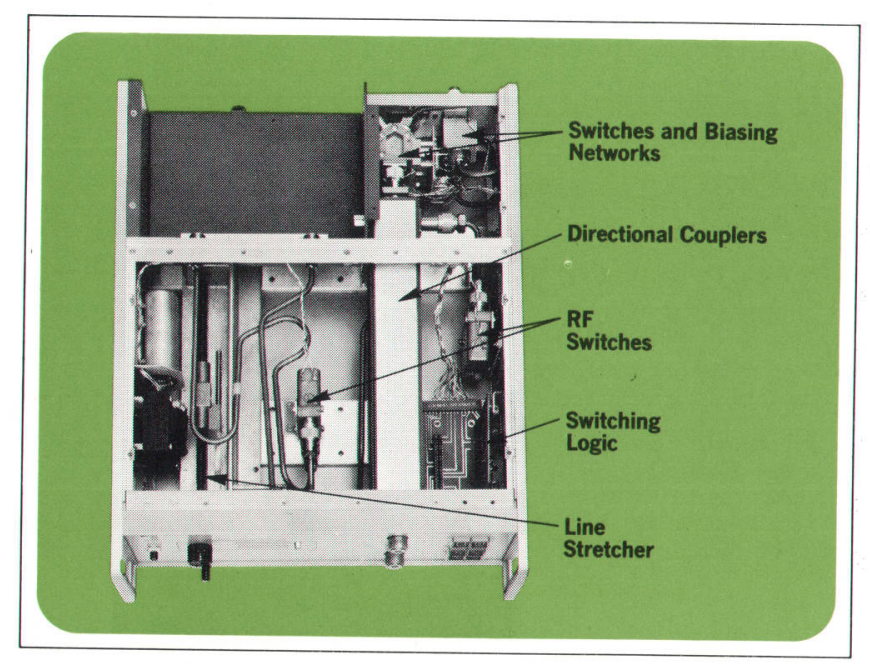

Fig. 3. Model 8745A S-Parameter Test Set.

direction to establish precise connections to various devices and accessories. Rear panel connections for remote programming are provided (the Test Set is used in the Model 8541A Computer-Controlled Automatic Network Analyzer System).

For testing devices that require bias, the Test Set contains biasing networks through which dc voltages can be applied to the center conductors of both directional couplers. The biasing networks themselves are outside the measurement circuit. To keep dc out of the signal source, there is a blocking capacitor on the signal-source side of these networks. There are also large capacitors next to the networks which act as low-impedance paths to ground for signals down to $10 \mathrm{kHz}$. This reduces signals below $100 \mathrm{MHz}$ which tend to be troublesome in higherfrequency measurements on active devices whenever there are long leads present, or when the dc supply being used has a high RF impedance. The biasing networks have rear-panel connections for bias current and bias voltage sensing.

Model 8743A Reflection-Transmission Test Unit, the high-frequency transducer instrument, has a different internal arrangement from the lower-frequency S-Parameter Test Set. The high-frequency Test Unit can make measurements with $10 \mathrm{~dB}$ less power at the test port. However, it can measure only two s-parameters; the device under test must be turned around to measure the other two. Also, the high-frequency Test Unit contains no internal biasing networks.

\section{Components Described}

The following paragraphs describe the directional couplers, line stretchers, switches, and flexible transmission lines that are used in the two transducer instruments.
Many of these components are also being manufactured separately.

\section{Exponential Directional Coupler}

When the network-analysis project began, typical directional couplers had useful bandwidths of only about one octave. This was the widest frequency range over which these couplers had high directivity $(>30 \mathrm{~dB})$ and flat coupling. This meant that to cover the analyzer frequency range of 0.1 to $12.4 \mathrm{GHz}$, seven couplers would be required - not a very convenient arrangement. Clearly, some new couplers had to be developed.

An idea for a broadband coupler came from a 1954 paper by B. M. Oliver. ${ }^{[4]}$ In this paper, the general form of the coupling equation for parallel lines is given as

$$
F(\omega)=\frac{j \omega}{v} \int_{0}^{l} k(z) e^{-2 j \omega z / v} d z,
$$

where $F(\omega)$ is the coupling coefficient as a function of frequency, $v$ is the velocity of propagation, $\omega$ is angular frequency, $k(z)$ is the coupling factor (assumed to be $<<1$ ), $z$ is the distance along the coupling members, and $l$ is the length of the coupling region. An ideal coupler would have $F(\omega)=$ constant from dc to infinity. However, this would require an infinitely long coupler and a coupling factor that isn't physically realizable. A more tractable coupling factor is an exponential one, that is,

$$
k(z)= \begin{cases}0, & z<0 \\ K_{o} e^{-z / z_{o}}, & z \geq 0\end{cases}
$$

where $K_{o}$ and $z_{o}$ are constants. This gives a coupling coefficient

$$
F(\omega)=\frac{K_{o}}{2} \frac{1}{1+\frac{v}{j 2 \omega z_{o}}}\left[1-e^{-l / z_{o}} e^{-j \omega \omega l / v}\right] .
$$

For $l=\infty$ the coupling curve is as shown in Fig. 4. It is a high-pass curve which, beyond a lower cutoff frequency, is quite flat with frequency. Of course, since the length $l$ cannot be infinite, any physically realizable coupler will have some ripple in the passband; the allowable amount of ripple and the cutoff frequency $\omega_{0}$ will determine $l$ and $z_{0}$. The important thing, however, is that exponential coupling makes very broadband flat couplers possible.

In the HP network-analyzer laboratory, R. W. Anderson and A. G. Ryals recognized that an exponential coupling factor $k(z)$ could be realized by using a slab-line transmission structure with two straight center conductors whose separation increased linearly with distance $z$. This is because the field in a slab transmission 


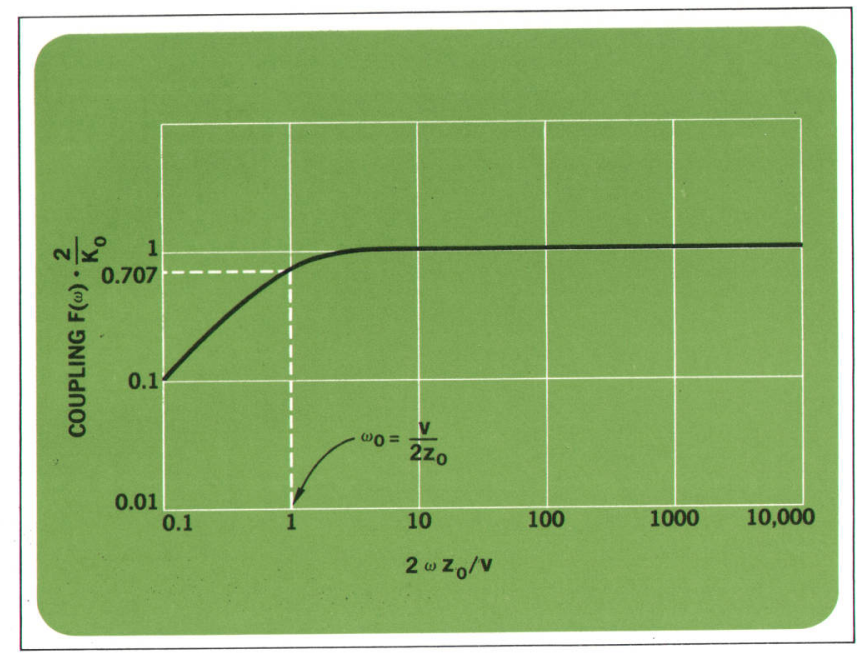

Fig. 4. This is a coupling-versus-frequency curve for an infinitely long directional coupler which has an exponential coupling factor. If the length of the coupler is finite, some ripple is introduced into the curve, but the coupler can still be very broadband. Only two such couplers are needed to cover the frequency range from 0.1 to $12.4 \mathrm{GHz}$.

line which has a single center conductor decays exponentially with distance away from the center conductor, provided that $d>>s$, where $d$ is distance away from the center conductor and $s$ is the spacing between the center conductor and the ground plane.

\section{Only Two Couplers Needed}

Using the exponential coupling concept, it was possible to cover the frequency range of 0.1 to $12.4 \mathrm{GHz}$ with only two directional couplers, the low-frequency version operating from 0.1 to $2 \mathrm{GHz}$ and the highfrequency version from 2 to $12.4 \mathrm{GHz}$. These couplers are built into the Model 8745A S-Parameter Test Set and the Model 8743A Reflection-Transmission Test Unit, respectively. These couplers have directivities of more than $30 \mathrm{~dB}$ and coupling coefficients of $20 \mathrm{~dB} \pm 1$ $\mathrm{dB}$ over their frequency ranges. Similar couplers are manufactured separately as Models 778D and 779D.

Fig. 5 is a photograph of the insides of the two types of exponential couplers.

\section{Coupler Design}

In an infinite slab line an infinite number of waveguide modes can propagate. Since the exponential couplers are basically slab lines, they had to be designed so that waveguide modes would be controlled. In the lower-frequency coupler the cross-sectional dimensions are kept small enough that no waveguide modes can propagate in the frequency band. That is, the slab line is terminated with a conducting wall at a point far enough away from the center conductors so it has negligible effect on the fields around the center conductors, yet close enough so the structure cannot propagate waveguide modes below $2 \mathrm{GHz}$.

In the high-frequency coupler the slab is physically terminated in a conducting wall, but a layer of polyiron is placed next to the wall, making the slab line appear electrically infinite at the frequencies where waveguide modes could exist. Also, the structure is symmetrical around the centerline of the slab line; there are no asyinmetries to produce high-order waveguide modes.

The low-frequency coupler is plastic-filled to reduce its physical length. In this coupler, the abrupt transition from $k(z)=0$ to $k(z)=K_{0}$ is produced by a right-angle turn on the auxiliary line. The corner is compensated for reactance both by the line geometry and by a tuning screw. The auxiliary line is terminated with another right-angle turn followed by a cylindrical resistor in a tapered outer conductor.

The high-frequency couplers are air-filled and use round-rod center conductors. The coupler used in the Model 8743A Reflection-Transmission Test Unit is designed to operate from 2 to $12.4 \mathrm{GHz}$ and uses a long polyiron load. The Model 779D Directional Coupler is designed to operate from 1.7 to $12.4 \mathrm{GHz}$ and uses

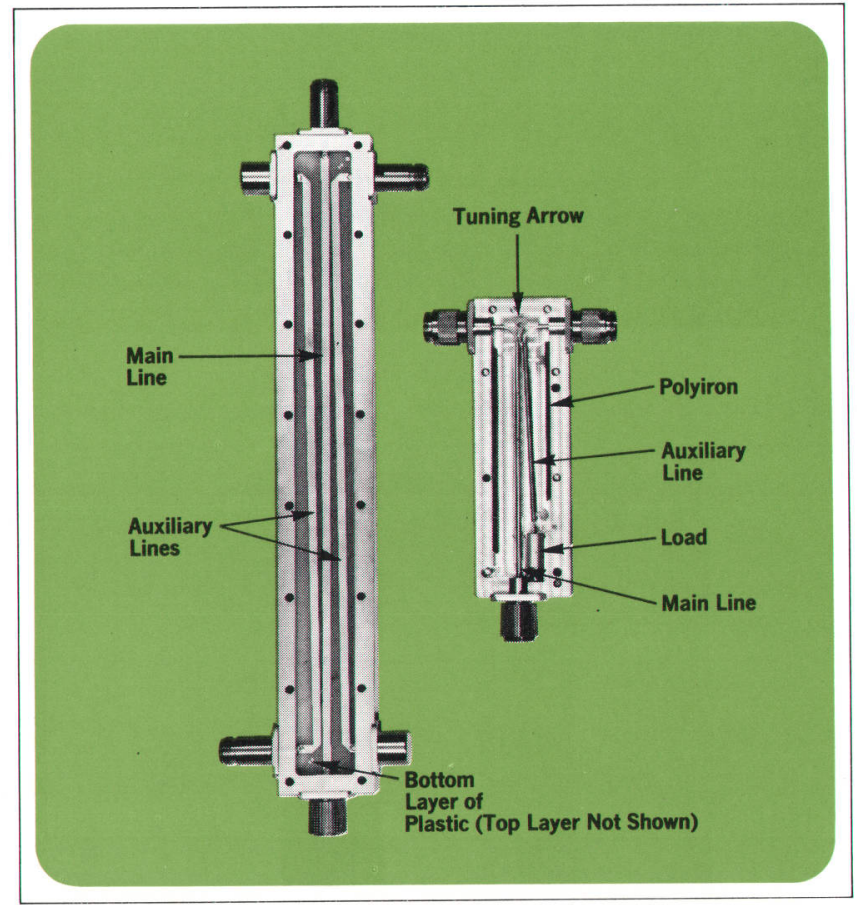

Fig. 5. Exponential couplers are slab transmission lines. The linearly increasing distance between the main and auxiliary lines gives the exponential coupling factor. The longer unit operates from 0.1 to $2 \mathrm{GHz}$, the shorter from 2 to $12.4 \mathrm{GHz}$. 


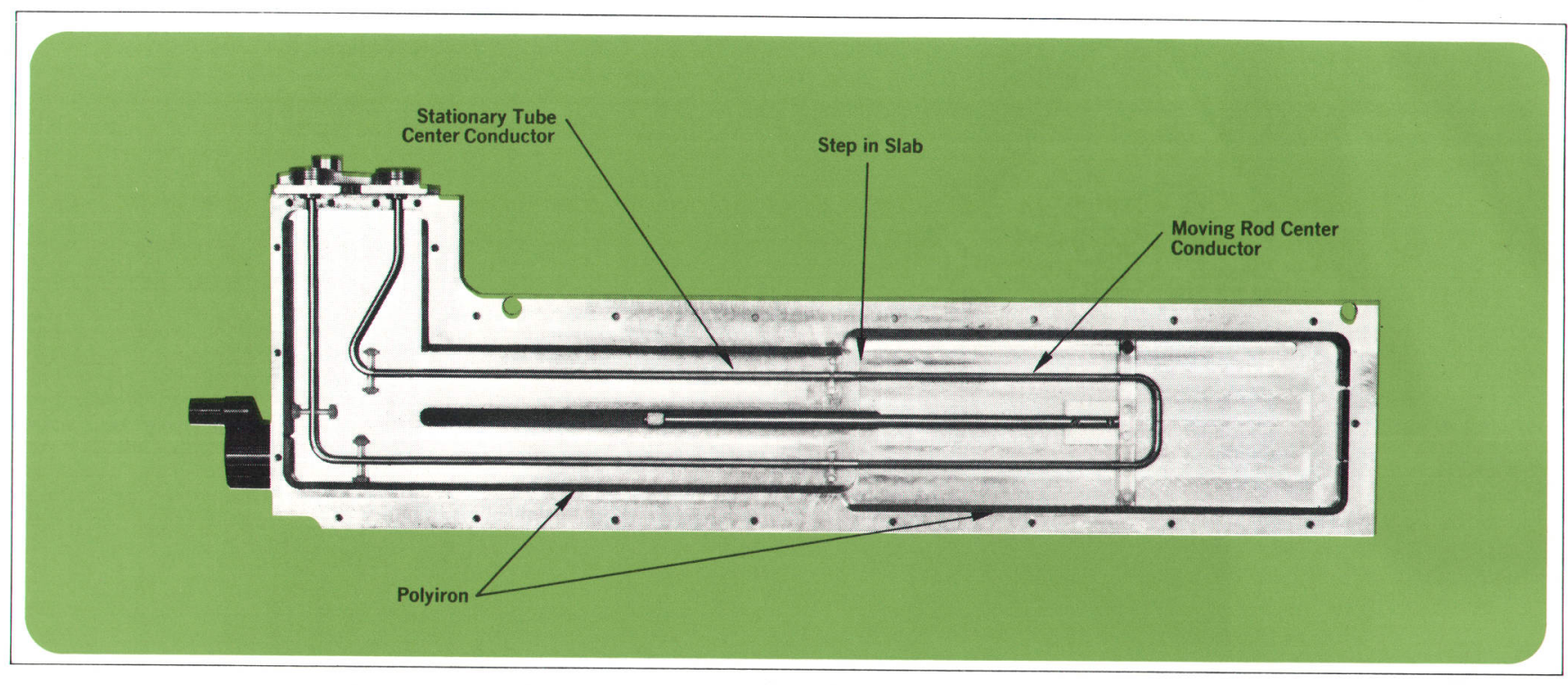

Fig. 6. This broadband (dc to $18 \mathrm{GHz}$ ) line stretcher has slab-line geometry so that only the center conductor has to move. The moving part is the rod section of a thin-walled tube-and-rod assembly. A step in the slab where the tube and rod join maintains a constant ratio of center-conductor diameter to slab depth; this keeps the characteristic impedance constant.

an evaporated $50 \Omega$ film termination on a ceramic substrate. The Model 779D is useful down to $.5 \mathrm{GHz}$ with directivity typically better than $30 \mathrm{~dB}$ but coupling falling off by 3 or $4 \mathrm{~dB}$, and useful above $12.4 \mathrm{GHz}$ although directivity is degraded.

In the high-frequency couplers, separation of the main and auxiliary lines at the start of the coupling area is achieved by forming both conductors to a 0.250 -inch internal radius, stepping the ground plane and reducing the cross section of the rods as shown in Fig. 5. Separation is further enhanced by a 'tuning arrow' (see Fig. 5) machined to create an interference fit with the slab line. Final coupler tuning is done with the slab line loose; when good directivity is achieved the tuning arrow is clamped in place by the slab line.

\section{Broadband Line Stretcher}

Because existing line stretchers were mechanically clumsy or lossy or had high VSWR, they were unsuitable for use in the network analyzer system. Consequently a new, precision, low-VSWR, constant impedance line stretcher was developed.

A slabline structure was chosen so the line could be stretched by moving only the center conductor. The slabline structure also allows sharp bends to be made in the center conductor without dispersion, since fields are concentrated above and below the center conductor. A constant impedance of $50 \Omega$ is maintained by moving the rod section of a thin-walled tube-and-rod construction, and machining a step in the slab at the joint to preserve a constant ratio of center-conductor diameter to slab depth (see Fig. 6).

The center-conductor tube is only 0.0025 inch thick. It is made of layers of gold and copper for high conductivity and nickel for mechanical rigidity. At the joints between the tube and the sliding rod, the tube is slotted to form contacting fingers. The slots are on the sides of the tube where the fields are lowest, and the ends of the tube are specially electroformed so contact is maintained without necking down the fingers; both of these techniques help to maintain constant impedance in the critical joint area.

Air dielectric is used in the line stretcher, and fields are in the TEM mode so electrical length is independent of frequency. Waveguide modes are suppressed by using polyiron loading at the edges of the slabline cavity; this is the same technique that was used in the high-frequency directional coupler to suppress waveguide modes. Center-conductor supports are as small as possible and are in low-field areas. Precise machining of the ground plane compensates for the supports and makes them nearly invisible electrically.

The line stretcher is driven by a zero-backlash, preloaded lead screw, and has a calibrated digital readout.

Fig. 6 shows the inside of the new line stretcher, which is used in the Model 8743A Reflection-Transmission 

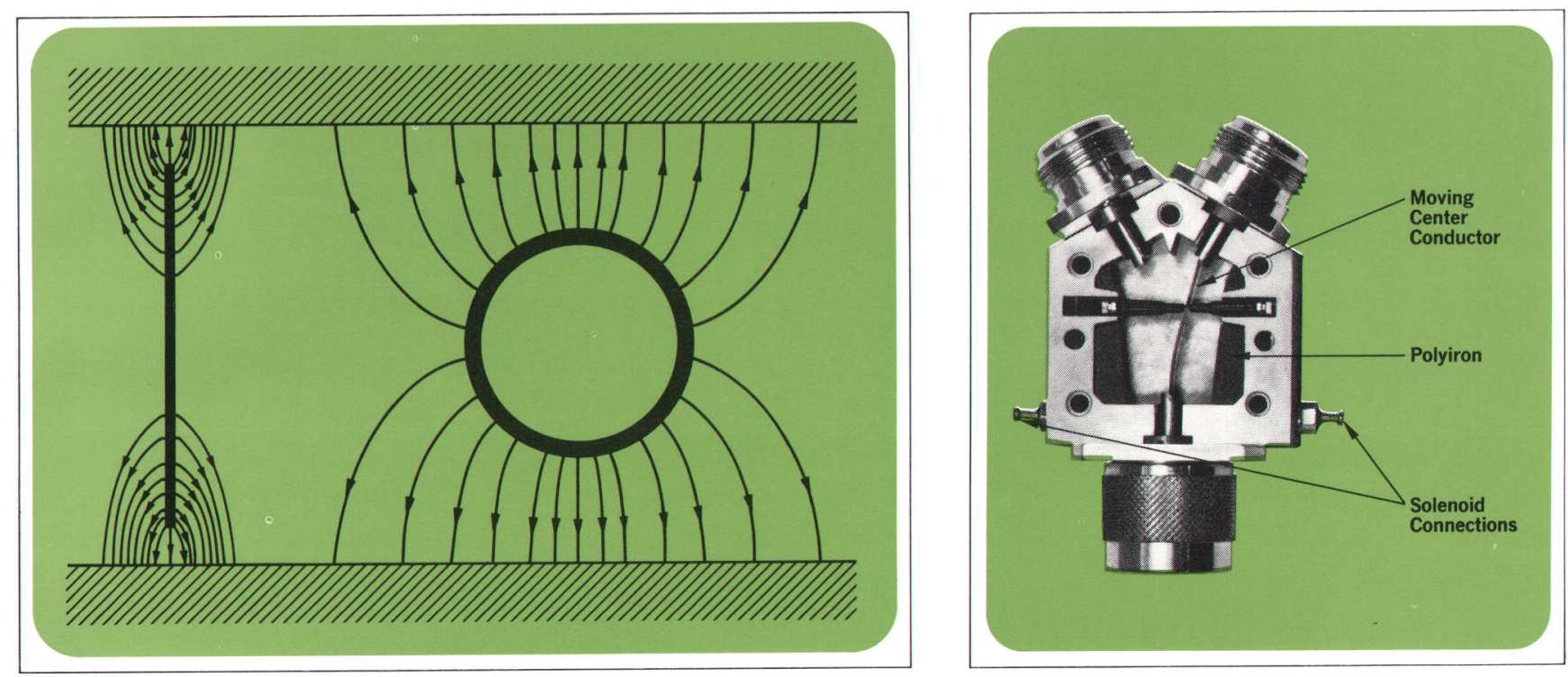

Fig. 7. In a slab line which has a thin center conductor (instead of a round one) the fields are extremely concentrated. This is good in a switch because it gives good isolation between output ports, and because the fields can follow the curve of the center conductor without dispersion. Fig. 8. Broadband (dc to $18 \mathrm{GHz}$ ) coaxial switches typically have insertion losses less than $0.5 \mathrm{~dB}$ and VSWR's less than 1.2. Isolation is greater than $50 \mathrm{~dB}$ at $12.4 \mathrm{GHz}$, and greater than $45 \mathrm{~dB}$ at $18 \mathrm{GHz}$.

Test Unit and the Model 8745A S-Parameter Test Set, and in the older HP reflection and transmission test units. It has a frequency range of 0 to $18 \mathrm{GHz}$, low VSWR (typically 1.15 at $12.4 \mathrm{GHz}$ ), and low loss (typically a change of $0.2 \mathrm{~dB}$ for $30 \mathrm{~cm}$ of stretch at $12.4 \mathrm{GHz}$ ).

\section{Coaxial Switches}

High VSWR, high insertion loss, and limited bandwidth in existing switches made it necessary to develop a new type of switch for the network analyzer system. As in the directional couplers and the line stretcher, slab-line geometry provided an answer.

In a slab transmission line the electric field is concentrated above and below the center conductor. If the center conductor is a flat, thin plate, perpendicular to the slabs, the field is even more concentrated, as shown in Fig. 7. The field is strongest near the edges of the center conductor. This field concentration is desirable if the center conductor has a number of reasonably sharp turns, or if the center conductor is movable, as it must be in a switch. Keeping the fields concentrated near the center conductor also improves isolation between the output ports in a switch.

The new switch developed for the network analyzer system uses this type of transmission line. Fig. 8 is a photograph showing the inside of the switch. It is a single-pole, double-throw switch which has a flexible center conductor suspended between two aluminum slabs and connected to $7 \mathrm{~mm}$ coaxial lines. The transitions from the coaxial lines to the special slab line are the contacting areas. The flexible center conductor is made of beryllium copper held to close tolerances to keep the characteristic impedance constant along the line and heattreated to ensure long life. Polyiron blocks inside the switch suppress the high-order waveguide modes.

These switches typically have VSWR's less than 1.2 from dc to $18 \mathrm{GHz}$, insertion losses less than $0.5 \mathrm{~dB}$, and isolations greater than $50 \mathrm{~dB}$ (at $12.4 \mathrm{GHz}$ ) between ports. Besides being used in the Model 8743A Reflection-Transmission Test Unit and the Model 8745A S-Parameter Test Set, they are manufactured separately as Model $8761 \mathrm{~A} / \mathrm{B}$. They are available with many different connectors, as well as with a built-in $50 \Omega$ termination on one port.

The activating, or drive mechanism for the switch is a magnetically latching solenoid. A $12 \mathrm{~V}$ (or $24 \mathrm{~V}$ ) pulse $20 \mathrm{~ms}$ long or longer will operate the switch, the direction of switching depending on the polarity of the pulse. The switching voltage can be applied continuously if desired, but only pulses are required. This is important in systems where power requirements and heat must be minimized. Switching speed including mechanical bounce is typically $30 \mathrm{~ms}$.

The mechanical design of the switches makes it possible for one switch to work into two others, as shown in Fig. 9. With this arrangement, the unused signal source 


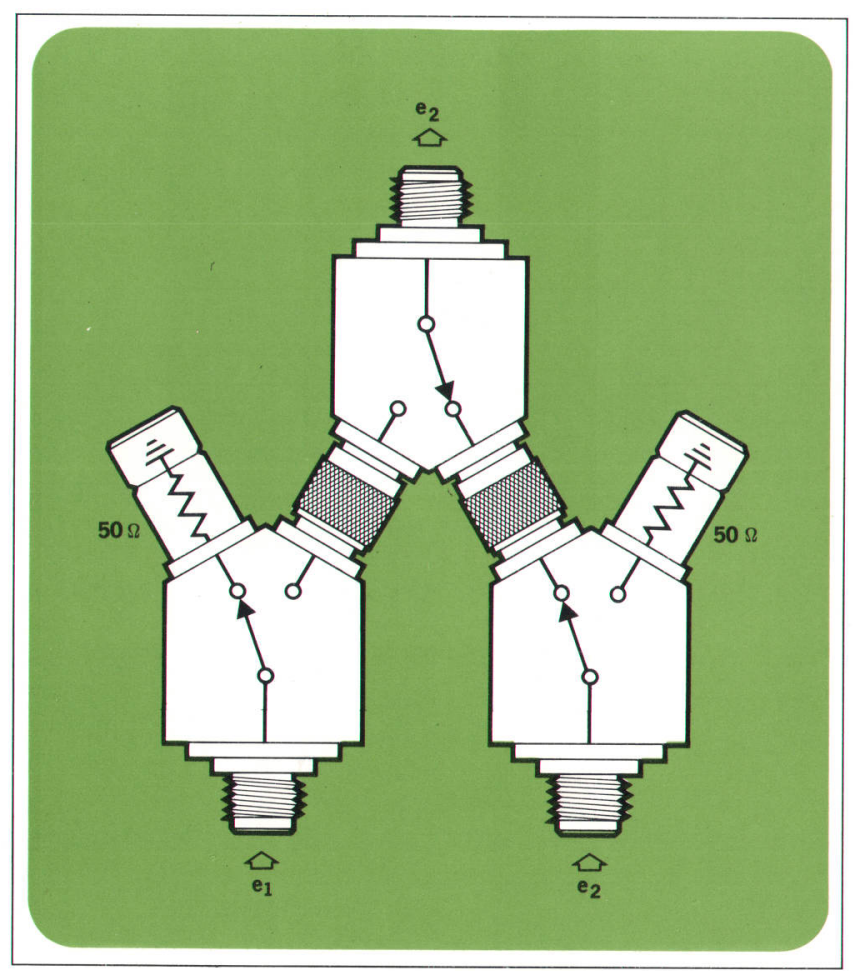

Fig. 9. When three switches are connected and terminated as shown, isolation between the unconnected ports is doubled, and the unused signal source is always terminated in its characteristic impedance. can always be terminated in its characteristic impedance, and isolation between the unconnected ports is doubled. Other arrangements of switches are possible. For example, a multiplexer unit can be built to switch several signal sources onto one line. The switches' low VSWR and insertion loss, wide frequency range, good isolation, and wide choice of connectors are especially valuable in complicated arrangements.

\section{Swivel Adapter}

During the early development stage of the network analyzer system it became obvious that flexible cables would be a problem if they were to be used in the measurement circuit between the measuring instrument and the unit under test. One problem is the reflection coefficient of a flexible cable, which is relatively high. Another problem is the change of phase and amplitude of the reflected and transmitted signals when the cable is moved.

A swivel adapter was designed as part of the solution to this problem. It consists of two $90^{\circ}$ bends with a rotating section between them (Fig. 10). With the adapter, a rigid coax line can be rotated to any position in a plane. If the connection to the swivel adapter is set to a particular angle the rigid line can be set to any solid angle.

The swivel adapter is intended to be used in the meas-

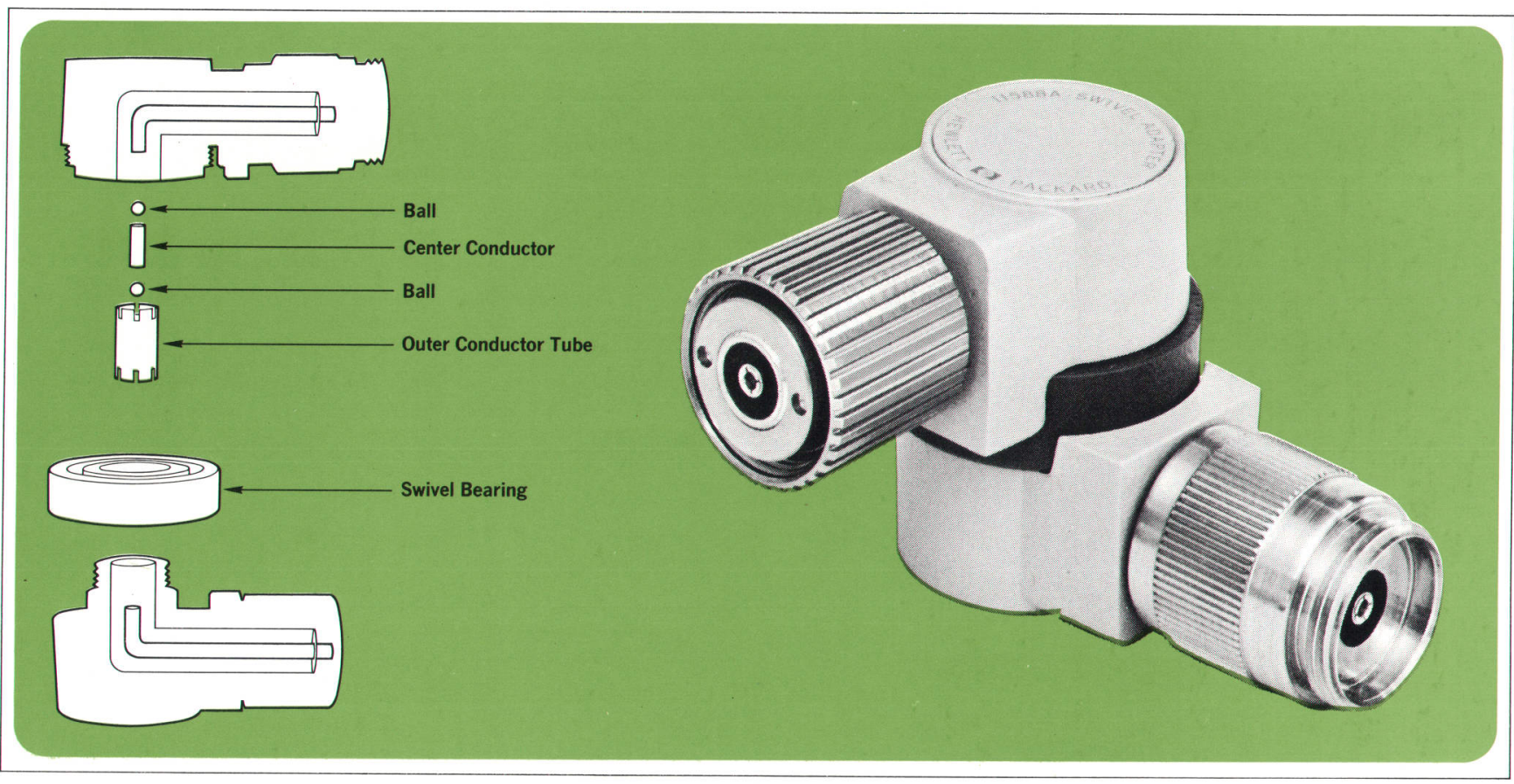

Fig. 10. Flexible cables couldn't be used in the network analyzer system because they have high reflection coefficients and because the phases and amplitudes of signals change when the cables are moved. To replace cables, this swivel adapter was developed, along with a rotary air line which uses the same double-ball-joint construction. Combinations of adapters and rotary lines can make the same connections that flexible cables can, yet have the accuracy of rigid coaxial lines. 
urement circuit and therefore is built with great care to insure a low standing wave ratio which changes very little as the swivel is rotated through $360^{\circ}$. Typically this change, or 'uncertainty vector,' is down $57 \mathrm{~dB}$ at $12.4 \mathrm{GHz}$ (a reflection coefficient variation of 0.0013 ) and down $70 \mathrm{~dB}$ below $8 \mathrm{GHz}$. These are large-angle variations, of course; small changes in the angle of the swivel normally produce much smaller changes in total reflected signal. The uncertainty vector changes transmission characteristics primarily in the form of mismatch loss; variations of transmitted phase and amplitude are virtually undetectable.

The swivel adapter's VSWR is below 1.10 from dc to $12.4 \mathrm{GHz}$. Although the VSWR and uncertainty vector are not as good at higher frequencies, the swivel adapter is useful to $18 \mathrm{GHz}$.

The swivel adapter center conductor rotates on two ball joints with a straight section of center conductor between them (Fig. 10). The use of two ball joints greatly reduces the problem of radial clearance in the mechanical bearing because the center conductor can shift and maintain good contact. The outer conductor coupling is formed by a thin-walled tube which is slotted to form expanding fingers that make contact only along the last 0.030 inch of each end of the tube. The tube is long enough and has enough spring so a small shift of the mechanical bearing radially will have very little effect.

Axial movement of the mechanical bearing is kept small and the motion in the center conductor is taken up by pre-loading the ball joints. The change in the outer conductor which accompanies axial motion or wear is a slight increase in the gap at the ends of the tube. However, the change is so small and the tube wall so thin that the electrical change is insignificant. What's more, tests equivalent to three years' normal use have produced negligible wear in the bearing.

\section{Rotary Air Line}

As often happens, when one problem is solved another becomes apparent. Such was the case with the new swivel adapter. The adapter was developed for use as a laboratory tool and is made only with APC-7 connectors. These connectors can tolerate only 1.5 foot-pounds of torque across their faces and 2.5 foot-pounds of rotational torque. Unfortunately, the swivel adapter connected to a section of rigid coaxial line forms a wrench which can easily exceed these torque limits. The likelihood that this will happen is quite high, since with the added degree of freedom an essentially rigid system of swivel adapters and air lines no longer feels rigid and

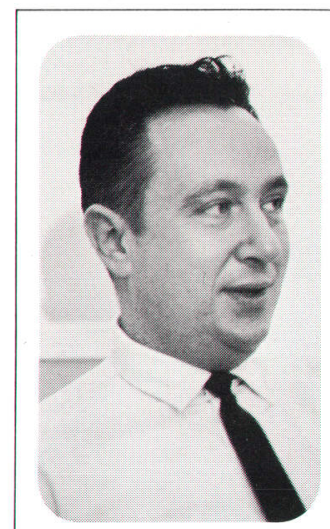

\section{Stephen F. Adam}

Steve Adam was a research and development engineer in Budapest, Hungary before he joined HP in 1957. At HP, Steve has supervised the development of coaxial wavemeters, thin-film coaxial attenuators, and the coaxial switches described in the accompanying article. He holds several patents and has others pending, mainly in the fields of transmission-line components and microwave instrumentation.

Steve holds the equivalent of an M.S. degree in mechanical and electrical engineering from the Technical Institute of Budapest. He is a member of IEEE and an instructor of microwave electronics at Foothill College. This year he was elected president of the Bay Area Council for Electronics Education. Steve is also currently serving on two IEEE committees, and on the Joint Industry Research Committee on Standardization of Miniature Precision Coaxial Connectors.

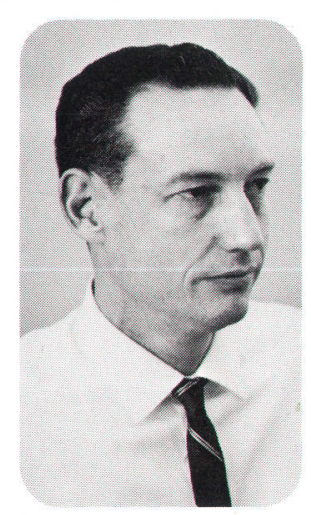

\section{George R. Kirkpatrick}

Bob Kirkpatrick has been developing waveguide and coaxial components for HP since 1956. Recently he has been project supervisor for many of the coaxial components and transducer instruments associated with the HP Network Analyzer system. Bob graduated from California State Polytechnic College in 1953 with a B.S. degree in electronics and radio engineering, and is now working toward an MSEE degree at the University of Santa Clara. He is the author of a paper on waveguide bridges.

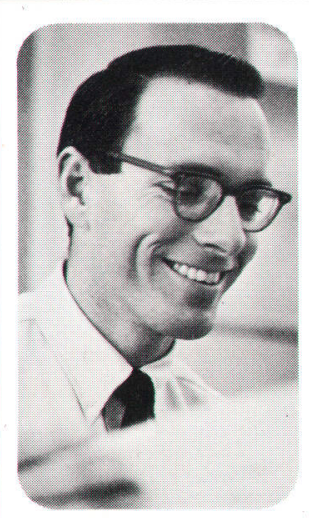

Richard A. Lyon

Dick Lyon received his B.S. degree in mechanical engineering from Stanford University in 1961 , and spent three years in the U.S. Army Intelligence Corps before joining HP in 1965. He has contributed to the design of several passive coaxial components and transducer instruments, and was project leader for the 8743A ReflectionTransmission Test Unit. He is now working for his M.S. degree in electrical engineering at Stanford. He is a member of Phi Beta Kappa.

Dick enjoys rowing, skiing, mountain climbing, and backpacking. He was a member of the U.S. fourwithout-coxswain rowing team in the 1964 Summer Olympic Games in Tokyo (the team won a bronze medal) and in the 1966 World Championships in Yugoslavia. 
the natural tendency is to try to move the assembly in any direction. To reduce the possibility of loosening or damaging the APC-7 connectors on the swivel adapter a rotary air line was developed using the same approach that was used for the swivel adapter. The rotary air line adds another degree of freedom to the system and eliminates potentially damaging forces while maintaining the high performance of the swivel adapter.

\section{Combinations Make Flexible Arms}

For use separately or with the 8745 A S-Parameter Test Set and the 8743A Reflection-Transmission Test Unit, swivel adapters, rotary air lines, and slab lines are combined to form the Model 11604A Universal Adapter and the Model 11605A Flexible Arm (see Fig. 2). Like flexible cables, these units allow for connecting the measuring system to devices of different shapes, sizes, and connector configurations. Unlike flexible cables, they have the accuracy of rigid air lines.

The swivel adapters and rotary air lines are also available separately as Models 11588A and 11606A. None of the rotary devices is intended to be motor driven.

\section{Acknowledgments}

Involved in the design of the 8745A S-Parameter Test Set were Richard Bauhaus, Kenneth Astrof, and Robert McCaw. Wilmot Hunter deserves a great deal of credit for the development of several components and accessories. David Veteran did the product design of the coaxial switches.

We also wish to thank Auber Ryals for his work which made the broadband couplers possible, and Richard Anderson for his direction and inspiration.

\section{References}

[1] W. M. Grove, 'A dc to $12.4 \mathrm{GHz}$ Feedthrough Sampler for Oscilloscopes and Other RF Systems', Hewlett-Packard Journal, Vol. 18, No. 2, October 1966.

[2] R. W. Anderson and O. T. Dennison, 'An Advanced New Network Analyzer for Sweep-Measuring Amplitude and Phase from 0.1 to $12.4 \mathrm{GHz}$, Hewlett Packard Journal, Vol. 18, No. 6, February 1967.

[3] R. W. Anderson, 'S-Parameter Techniques for Faster, More Accurate Network Design', Hewlett-Packard Journal, Vol. 18, No. 6, February 1967.

[4] B. M. Oliver, 'Directional Electromagnetic Couplers', Proceedings of the IRE, Vol. 42, p. 1686, November 1954.

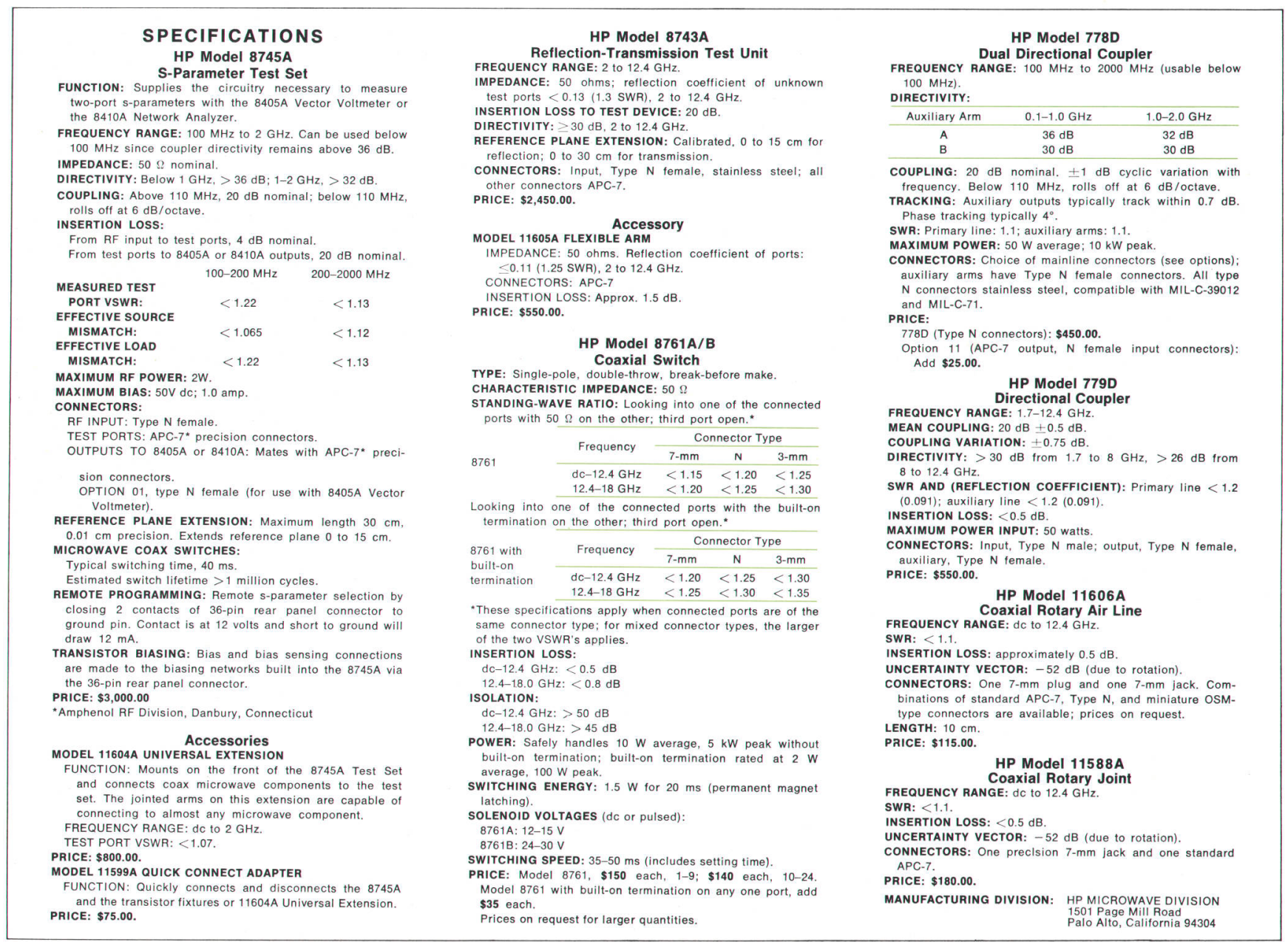




\section{Measuring High-Frequency Transistor Parameters}

If you have the right instruments, high-frequency transistor measurements are very simple. Here is the method, along with some advice on taking and interpreting data.

\section{By Richard H. Bauhaus}

TRANSISTOR UPPER FREQUENCY LIMITS $\left(f_{t}\right)$ are now in the gigahertz range and are getting higher every day. To design circuits around these transistors using today's techniques, it's essential to be able to make accurate, dependable measurements of their s-parameters. ${ }^{[1]-[3]}$

High-frequency transistor measurements are very simple if you have this equipment:

- A network analyzer (HP 8410A) or vector voltmeter (HP 8405A)
- A compatible signal source (HP 8690B/8699B or HP 3200B)

- An s-parameter test set (HP 8745A, described near the beginning of the preceding article)

- Transistor fixtures for the test set (HP 11600A and $11602 \mathrm{~A})$ and calibration sets for the fixtures (HP $11601 \mathrm{~A}$ and $11603 \mathrm{~A})$

- A transistor bias supply (HP 8717A).

Typical measurement setups are illustrated in Fig. 1.

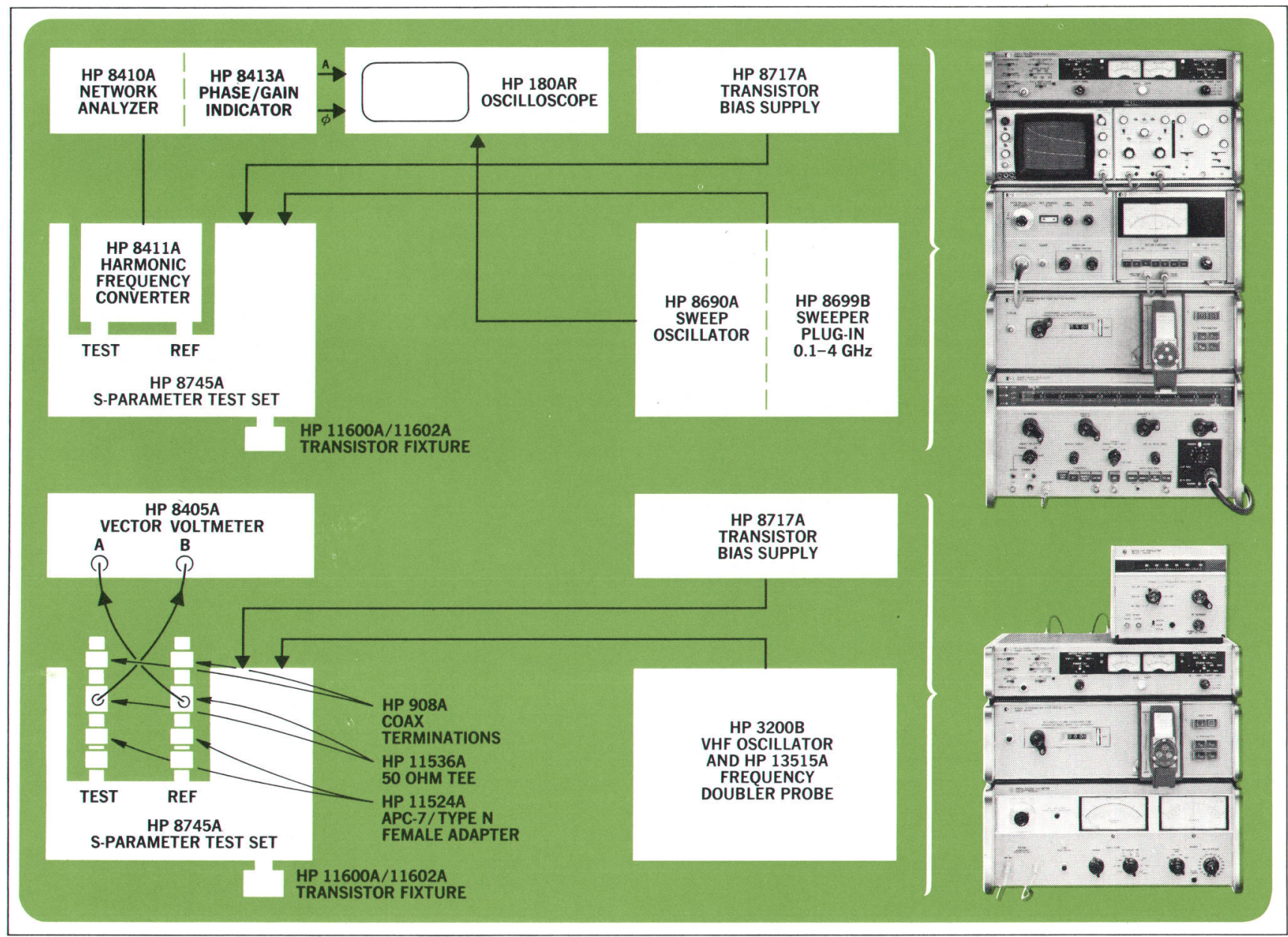

Fig. 1. Typical setups for measuring transistor s-parameters. The network analyzer system (top) makes swept measurements from 0.1 to $2 \mathrm{GHz}$. The vector voltmeter system (bottom) makes fixed-frequency measurements from $30 \mathrm{MHz}$ to $1 \mathrm{GHz}$. 


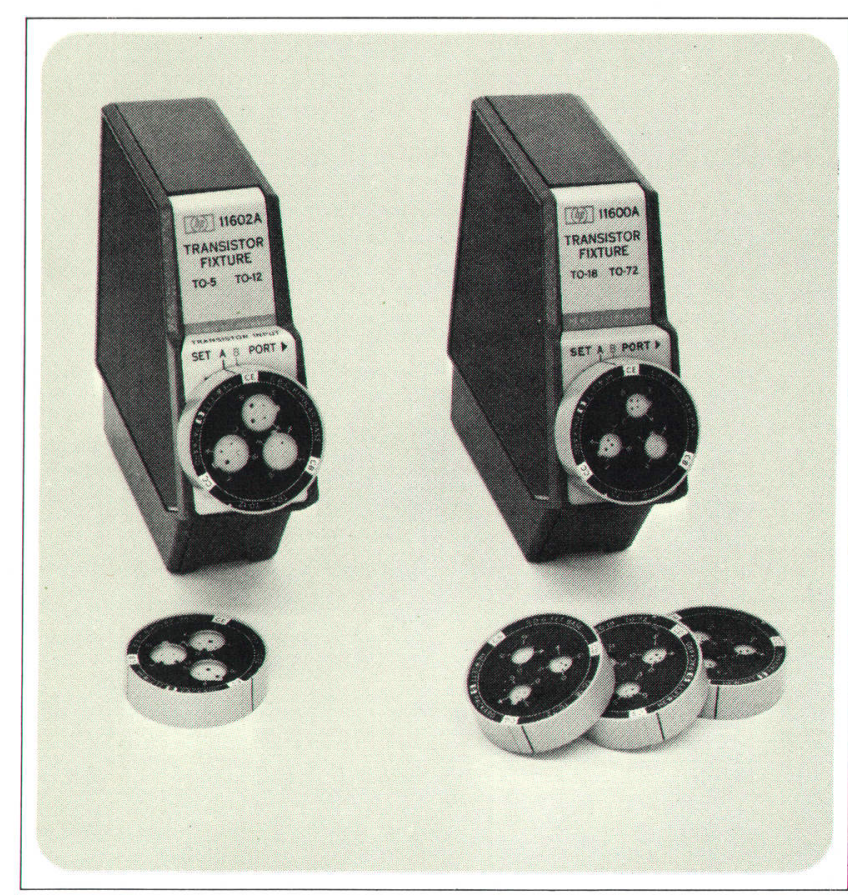

Fig. 2. Transistor fixtures have snap-on pin identifying masks which tell where to insert the transistor leads. The fixtures swallow leads up to 1.5 inches long and take them completely out of the measurement.

\section{Transistor Fixtures}

The business end of the measurement setup is one of the two transistor fixtures, Fig. 2. One fixture is for transistors in TO-18 or TO-72 packages and the other is for transistors in TO-5 or TO-12 packages. Both fixtures attach directly to the front of the s-parameter test set and are usable from dc to $2 \mathrm{GHz}$ (the s-parameter test set operates from 0.1 to $2 \mathrm{GHz}$ ).

The fixtures are basically precision $50 \Omega$ transmission lines that come right up to the header of any transistor whose leads are fully inserted into them. The fixtures can swallow up any lead length from 0.03 inch to 1.5 inches; this takes the leads completely out of the measurement.

Because the transmission lines are fixed, the transistor must be inserted differently depending on which lead is to be common and on the relative positions of the emitter, base, and collector leads. To make it easy to insert the transistor properly, a pin identifying mask can be snapped into place on the fixture and rotated to one of three positions, one for each of the common-lead configurations. The mask shows exactly where to insert each of the leads. There are standard masks for EBC and BEC bipolar transitor headers and for SGD and SDG fieldeffect transistor headers, and other masks are available on special order.
There are also calibration standards for the fixtures a short, a $50 \Omega$ through line, and a $50 \Omega$ load - which can be used to establish an accurate reference plane for the measurement. The reference plane is where the header of the transistor rests when it is fully inserted into the fixture. The calibration standards can also be used to measure system errors. It then becomes possible to achieve very high accuracies by removing these errors from the raw data; this is done in the HP 8541A Automatic Network Analyzer System. ${ }^{[4],[5]}$

\section{Transistor Bias Supply}

The transistor bias supply, Model 8717A, was developed to provide a fast, convenient means for applying bias to the transistors in the test fixtures. Fig. 3 shows the front panel of the bias supply. Bias conditions are selected by means of switches and are applied to the transistor by pressing the BIAS ON button. The button lights when bias is applied.

Accuracy and stability of the bias conditions are maintained by a feedback system in the bias supply. The transistor being tested is an integral part of this system, even when the transistor is as much as 10 feet away.

For use in computer controlled systems, such as the HP 8541A Automatic Network Analyzer, the transistor bias supply can be converted into a digitally programmable instrument by installing a plug-in board.

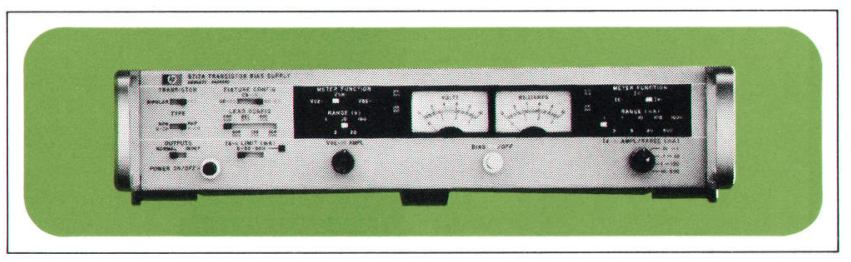

Fig. 3. Model 8717A Transistor Bias Supply has slide switches for rapid selection of bias conditions. The transistor being biased is an integral part of a feedback system in the supply which maintains the accuracy and stability of the bias conditions.

\section{How to Measure}

Here's how to measure the s-parameters of a transistor with the network analyzer setup of Fig. 1.

- Select the proper transistor fixture and mask for the transistor being tested. Connect the fixture to the s-parameter test set, snap the mask into place, and rotate the mask to the common lead configuration you want to use.

With the sweeper sweeping from 0.1 to $2 \mathrm{GHz}$, calibrate the system. Insert the standard short into the transistor fixture. Push the $s_{11}$ button on the 
s-parameter test set and select the proper input port (the mask and the fixture tell which port to select); then set the amplitude controls of the network analyzer for a $0 \mathrm{~dB}$ gain indication. Next set the reference plane for the measurement by adjusting the line stretcher in the s-parameter test set and the network analyzer's phase controls until the analyzer shows a constant $180^{\circ}$ phase shift.

- Select the s-parameter you want to measure by pushing a button on the s-parameter test set.

- Set the bias conditions on the front-panel switches of the transistor bias supply.

With bias and RF power off, insert the transistor into the fixture.

- Apply bias and RF power, and observe the results on the network analyzer and the oscilloscope.

\section{How Much Is Too Much?}

The higher the input power in the system of Fig. 1, the easier it is for the network analyzer or vector voltmeter to lock solidly to the signals that are being measured. However, since the s-parameters normally are used to characterize a transistor when it is operating as a smallsignal or linear device, care must be taken in testing the transistor to avoid overdriving it and distorting the values of the s-parameters. Most of the difficulty is caused by driving the input current, $i_{1}$, to levels that result in distortion or clipping. The greatest variations in input cur- rent occur when $s_{21}$ is being measured in the commonemitter configuration, so this is when the greatest care is called for.

The quickest and easiest method for determining whether distortion is occurring is to measure $s_{21}$ at the lowest possible input power level and compare that to a measurement of $s_{21}$ at a higher input level. If $s_{21}$ changes, the transistor is being overdriven at the higher input level. Once a good input power level is found for measuring $s_{21}, s_{11}$ should be measured at about the same level. Typically, $s_{22}$ and $s_{12}$ can be measured with 10 to $20 \mathrm{~dB}$ more input power without distorting their values.

The maximum allowable input power for measuring an undistorted $s_{21}$ also can be determined by calculation. The problem becomes one of estimating the peak input current, $I_{L 1}$, where clipping occurs or distortion becomes objectionable. A first order estimate of $I_{L 1}$ is

$$
\boldsymbol{I}_{L 1}=\frac{\boldsymbol{I}_{c}}{2} \sqrt{\frac{1}{\beta_{o}{ }^{2}}+\left(f / f_{t}\right)^{2}},
$$

where $I_{c}$ is dc collector current, $\beta_{o}$ is dc beta, $f$ is frequency of measurement, and $f_{t}$ is $\beta$-cutoff frequency. With this estimate of $I_{L 1}$, the allowable input power for an undistorted measurement of $s_{21}$ in a $50 \Omega$ system can be calculated using this equation:

$$
P_{a} \leq \frac{25 I_{L 1}{ }^{2}}{\left|1-S_{11}\right|^{2}} .
$$

\section{Printed-Circuit Slide Switches Save Panel Space}

Small front-panel size was one of the objectives in the design of the Transistor Bias Supply described in the accompanying article. Faced with the problem of satisfying complex switching needs in minimum space, the instrument's designers chose a printed-circuit slide switch, also designed at HP.

Fabrication of the switch starts with a printed-circuit board on which contacts and interconnections are made using nearly standard printed-circuit techniques. Molded nylon rails are then riveted to the board. Molded acetal plastic slides ride in grooves in the rails, and a wire spring provides detent action along the molded detail on the rails. Palaney slide contacts are mounted in the plastic slides and make contact to the printed contacts on the board.

The switches can accommodate very complex interconnections. They are small, inexpensive, and highly reliable.

Credit for the original concept and design of the switches goes to Ned R. Kuypers and Larry L. Ritchie.

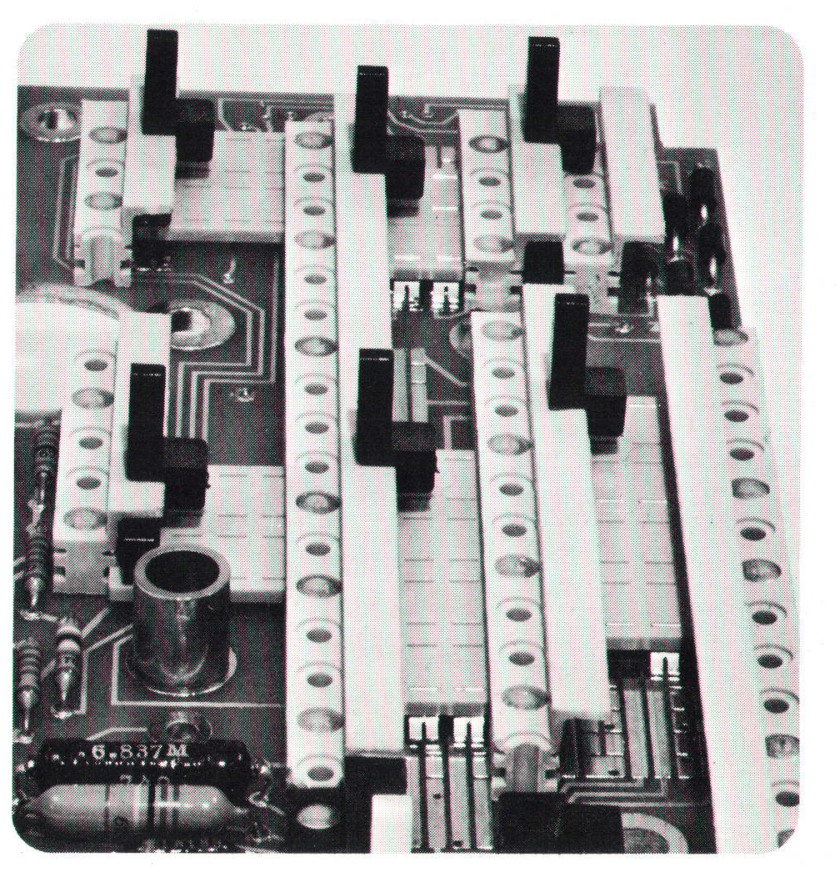


The value of $s_{11}$ can be obtained from a measurement at a very low input power level. This equation should pre$\operatorname{dict} P_{a}$ within approximately $3 \mathrm{~dB} \cdot{ }^{[6]}$

\section{Acknowledgments}

I am much indebted to an inspired design team that tackled difficult objectives and succeeded admirably. My associates in the design of the transistor fixtures and accessories were Kenneth Astrof and Robert McCaw. Working with me on the transistor bias supply were Earle Ellis and Elwood Barlow. Roger Wong provided invaluable assistance on the experimental and theoretical work on transistor s-parameter distortion.

\section{References}

[1] HP Application Note 91, 'How Vector Measurements Expand Design Capabilities.'

[2] HP Application Note 92, 'Network Analysis at Microwave Frequencies.'

[3] HP Application Note 95, 'S-Parameters - Circuit Analysis and Design.'

[4] R. Hackborn, 'An Automatic Network Analyzer System,' Microwave Journal, May 1968.

[5] HP Application Note 99, '8541A Automatic Network Analyzer Measurement Capabilities.'

[6] HP Application Note, 'Large-Signal Transistor S-Parameter Measurements,' to be published.

\section{Bibliography}

Sources of information on transistor concepts and modeling. 1. 'Physical Electronics and Circuit Models of Transistors,' Semiconductor Electronics Education Committee (SEEC), Wiley, 1964, Vol. 2, Chapts. 2 and 9, and pp. 32-40, 121-145, and 149-152.

2. J. Millman and C. C. Halkias, 'Electronic Devices and Circuits,' McGraw-Hill, 1967, pp. 369-378.

3. A. B. Phillips, 'Transistor Engineering,' McGraw-Hill, 1962, pp. 289 and 298-305.

4. J. Millman and H. Taub, 'Pulse, Digital, and Switching Waveforms,' McGraw-Hill, 1965, pp. 7-8, 12-15, and 121-126.

5. R. F. Shea, ed., 'Amplifier Handbook,' McGraw-Hill, 1966.

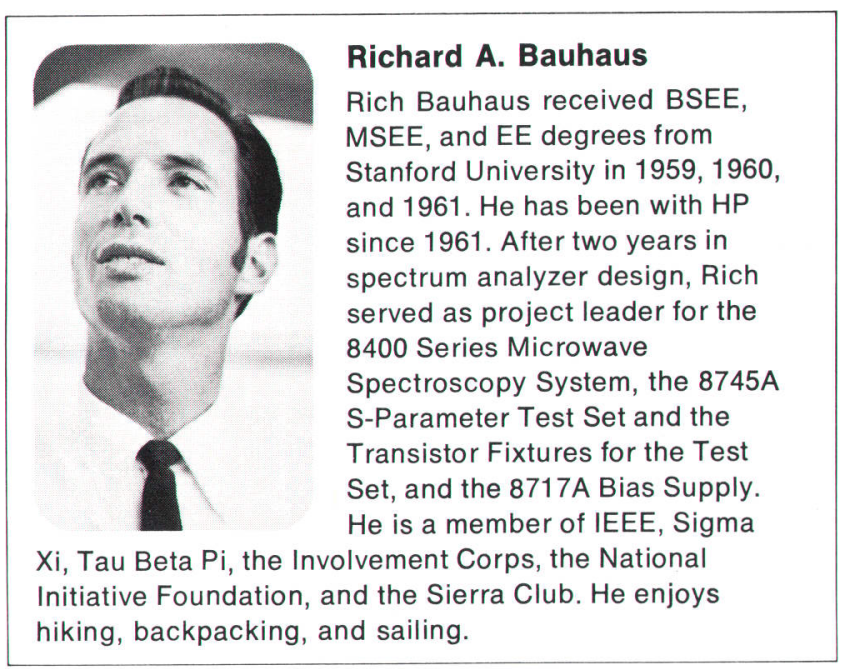

\begin{abstract}
SPECIFICATIONS HP Model 8717A Transistor Bias Supply

INSTRUMENT TYPE: Transistor bias supply with two modes of operation, NORMAL and INDEPENDENT. NORMAL is used to bias transistors. INDEPENDENT switches the two internal supplies into a voltage supply and an independent current supply. OPTION 01: Digital/analog converter for remote programming (typical).

SPECIFICATIONS: See Table at right. PRICE: $\$ 1295.00$

OPTION 01: Programmable D/A Converter, add $\$ 50000$
\end{abstract}

\begin{tabular}{|c|c|c|}
\hline & MANUAL & PROGRAMMED \\
\hline & NORMAL INDEPENDENT & NORMAL INDEPENDENT \\
\hline \multirow{2}{*}{$\begin{array}{l}\text { OUTPUTS: } \\
\text { dc voltage }\end{array}$} & continuously variable & variable in $0.25 \mathrm{~V}$ steps \\
\hline & $\begin{array}{cc}\mathrm{V}_{C E}\left(\mathrm{~V}_{\mathrm{DS}}\right) & 0-31.75 \mathrm{Vdc} \\
0-31.75 \mathrm{Vdc} & @ 500 \mathrm{~mA}\end{array}$ & Same as MANUAL \\
\hline \multirow[b]{3}{*}{ dc current } & continuously variable & \multirow{2}{*}{$\begin{array}{c}\text { step }=3.13 \% \text { full scale } \\
\text { current range } \\
\text { Same as MANUAL }\end{array}$} \\
\hline & 4 ranges 3 ranges & \\
\hline & $\begin{array}{rr}0.01-1 \mathrm{~mA} & 0.01-1 \mathrm{~mA} \\
0.1-10 \mathrm{~mA} & 0.1-10 \mathrm{~mA} \\
1.0-100 \mathrm{~mA} & 1.0-100 \mathrm{~mA} \\
10-500 \mathrm{~mA} & @ \pm 10 \mathrm{Vdc}\end{array}$ & $\begin{array}{cc}0.016-1 \mathrm{~mA} & 0.016-1 \mathrm{~mA} \\
0.16-10 \mathrm{~mA} & 0.16-10 \mathrm{~mA} \\
1.6-100 \mathrm{~mA} & 1.6-100 \mathrm{~mA} \\
16-1000 \mathrm{~mA} & @ \pm 10 \mathrm{Vdc} \\
\text { (500mA max } & \\
\text { output) } & \end{array}$ \\
\hline Voltage Accuracy & $\pm 4 \%$ of meter full scale & $\begin{array}{l} \pm(0.2 \mathrm{Vdc}+2 \% \text { of } \\
\text { programmed value) }\end{array}$ \\
\hline Current Accuracy & $\pm 4 \%$ of meter full scale & $\begin{array}{l} \pm(5 \mu \mathrm{A}+2 \% \text { of } \\
\text { programmed value })\end{array}$ \\
\hline $\begin{array}{l}\text { OVERLOAD } \\
\text { PROTECTION: }\end{array}$ & $\begin{array}{cc}\mathrm{I}_{\mathrm{E}}\left(\mathrm{I}_{\mathrm{S}}\right) & \text { Current } \\
5,50,500 \mathrm{~mA} & 5,50 \mathrm{~mA} \\
(+20 \%,-0 \%) & (+20 \%,-0 \%)\end{array}$ & Same as MANUAL \\
\hline $\begin{array}{l}\text { VOLTAGE METER: } \\
\text { Function }\end{array}$ & $\begin{array}{c}V_{C E}, V_{B E}, V_{C B} \\
\left(V_{O S}, V_{D G}, V_{G S}\right)\end{array}$ & Same as MANUAL \\
\hline Ranges & $1,3,10,30,100 \mathrm{~V}$ & \multirow{2}{*}{$\begin{array}{l}\text { Same as MANUAL } \\
\text { Same as MANUAL }\end{array}$} \\
\hline $\begin{array}{l}\text { CURRENT METER: } \\
\text { Function }\end{array}$ & $\begin{array}{c}I_{E}, I_{C}, I_{B} \\
\left(I_{S}, I_{D}, I_{G}\right)\end{array} \quad$ Current & \\
\hline Ranges & $\begin{array}{c}0.1,0.3,1,3,10,30,100 \\
300,1000 \mathrm{~mA}\end{array}$ & Same as MANUAL \\
\hline $\begin{array}{l}\text { LOAD REGULATION: } \\
\text { Constant Voltage }\end{array}$ & \multicolumn{2}{|c|}{$\leq 0.2 \%+20 \mathrm{mV}$ when current varies from $0-500 \mathrm{~mA}$} \\
\hline Constant Current & \multicolumn{2}{|c|}{$\begin{array}{l}\leq 1.0 \% \text { when voltage varies from } \\
0-10 \vee \text { (for current ranges } \leq 100 \mathrm{~mA} \text { ) }\end{array}$} \\
\hline $\begin{array}{l}\text { LINE REGULATION: } \\
\text { Constant Voltage }\end{array}$ & \multicolumn{2}{|c|}{$\leq 0.05 \%+30 \mathrm{mV}$ with $\pm 10 \%$ power line change } \\
\hline Constant Current & \multicolumn{2}{|c|}{$\leq 0.001 \%+1 \mu \mathrm{A}$ with $\pm 10 \%$ power line change } \\
\hline $\begin{array}{l}\text { RIPPLE: } \\
\text { Constant Voltage }\end{array}$ & \multicolumn{2}{|c|}{$\leq 20 \mathrm{mV}$} \\
\hline Constant Current & \multicolumn{2}{|c|}{$\leq 100 \mu \mathrm{A}$} \\
\hline $\begin{array}{l}\text { TRANSIENT } \\
\text { RECOVERY: } \\
\text { Voltage }\end{array}$ & \multirow{2}{*}{\multicolumn{2}{|c|}{$\begin{array}{l}\text { Recovery to within } 1 \% \text { of final value } \leq 500 \mu \text { s (typical) } \\
\text { Recovery to within } 1 \% \text { of final value } \leq 20 \mathrm{~ms} \text { (typical) }\end{array}$}} \\
\hline Current & & \\
\hline
\end{tabular}

SPECIFICATIONS

HP Models 11600A and 11602A Transistor Fixtures

FUNCTION: Holds devices for s-parameter measurements in a 50-ohm coax circuit. Either fixture provides common emitter, base, and collector for bipolars, and common source, gate, and drain tor fiodes, etc.).

TRANSISTOR BASE PATTERNS

MODEL 11600A: Accepts TO-18/TO-72 packages. Will also accept any 3 or 4 lead package with leads that lie on a 100 mil circle and whose diameters are 16 to 19 mils. MODEL 11602A: Accepts TO-5/TO-12 packages. Will also accept any 3 or 4 lead package with leads that lie on a
200 mil circle and whose diameters are 16 to 19 mils.

LEAD LENGTHS: Up to 1.5 inches long.

FREQUENCY RANGES: do to $2 \mathrm{Ghz}$ nominal.

IMPEDANCE: $50 \Omega \pm 2 \Omega$.

vSWR:

$11600 \mathrm{~A}<1.1$ from dc to $2.0 \mathrm{GHz}$

$11602 \mathrm{~A}<1.15$ from dc to $2.0 \mathrm{GHz}$.

CONNECTORS: APC- $7^{*}$ precision connectors for input and

output are standard.
OPTION 01: Precision Type $\mathrm{N}$ connectors for input and output.

*Amphenol RF Division, Danbury, Connecticut.

PRICE: $\$ 425.00$.

ACCESSORIES

MODEL 11601A and 11603A Calibration Kits for Transistor

Fixtures.
FUNCTION: To calibrate the $11600 \mathrm{~A}$ and $11602 \mathrm{~A}$ respec-

tively. Each kit has three calibration references.

REFERENCES INCLUDED:

1. Short circuit termination.

2. $50 \Omega$ through section.

3. the fixtures.

PRICE: $\$ 75.00$.

MANUFACTURING DIVISION: HP MICROWAVE DIVISION 1501 Page Mill Road 


\title{
Recording Data for Computer Analysis
}

\author{
This modular digital coupler, together with a recording de- \\ vice, translates the digital outputs of voltmeters, counters, and \\ other instruments into computer-compatible digital records.
}

By William J. Steinmetz and Robert L. Knapp

HOW MANY INSTRUMENTS are there in your laboratory that have digital outputs? Digital voltmeters typically have them. So do counters, nuclear scalers, quartz thermometers, and many other instruments. How often do you use the digital outputs? Probably never, if you're a typical engineer or scientist using these instruments for research and development. Would it help you to use the digital outputs? Very often it would. Suppose, for example, that you're testing a breadboard discriminator with a signal source, a counter, and a digital voltmeter. You want to make a series of measurements of various input frequencies and the discriminator's corresponding output voltages, and then calculate the linearity of the circuit. You can, of course, record and analyze the data by hand. However, if you have access to a computer or to a time-sharing terminal, as most people do, it would be much easier if the data could be recorded automatically on punched tape, magnetic tape, or punched cards, and then fed into the computer for analysis. The more complex the problem, the greater the advantage of recording and analyzing the data automatically.

\section{Flexible Digital Coupler}

Automating the data recording process takes a digital coupler and a recording device. The coupler translates the binary-coded-decimal (BCD) outputs of instruments into a serially coded digital record on any one of several computer-compatible input media such as punched tape, magnetic tape, or punched cards.

Many couplers are designed to operate with one specific instrument and to record exclusively on one type of recording device. In this respect the new HP Model 2547A Coupler (Fig. 1) is quite different. It has modular input and output printed-circuit boards which can be arranged in a variety of different combinations to meet the continually changing data-recording needs of the typical laboratory. The new coupler can accept BCD data from as many as six instruments, and can drive any one of eight recording devices. The recording devices are the
ASR 33 and ASR 35 Teletypes, the Kennedy 1406 and 1506 Incremental Magnetic Tape Recorders, the IBM 526 Card Punch, the IBM Model B Electric Typewriter, the Friden 2303 Flexowriter, and the Tally 120 High Speed Paper Tape Punch. The HP 5050B Digital Recorder can be driven simultaneously with any of the other devices. Changing from one recording device to another is a simple matter of changing the device and the associated printed-circuit output boards in the coupler.*

\section{Controllable Output Format}

Because different computer programs and programming languages require different data formats, the new coupler's output format is controllable. The coupler's basic data word can be as long as 20 digits or as short as necessary. An internal patch panel arranges the recorded characters in any desired order regardless of their relationship at the output of the measuring instrument.

* All of the output options for the Model 2547A Coupler except the card punch normally include the recording device as well as the output boards. This is because most of the recording devices are modified to meet HP specifications. This policy also permits complete factory checkout of each operating system.

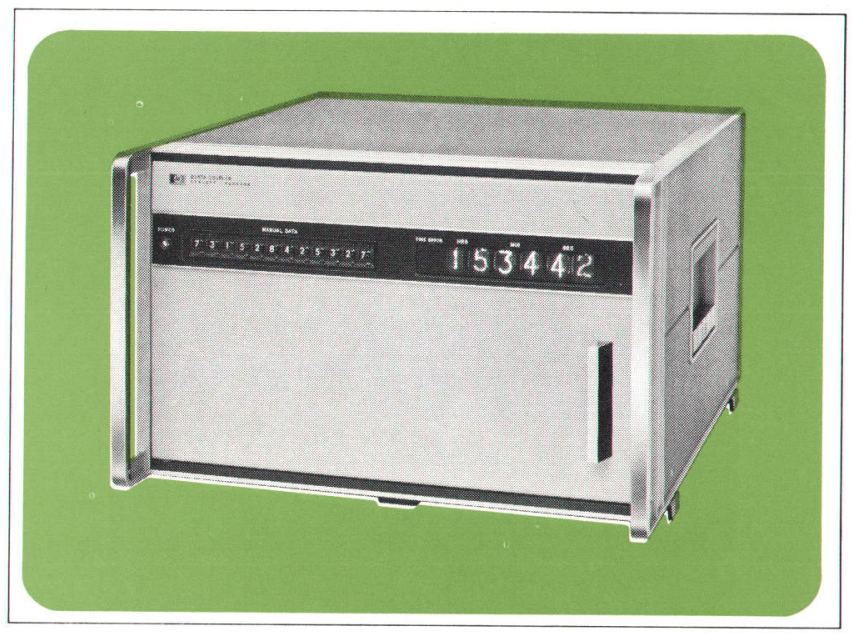

Fig. 1. Model 2547A Coupler translates binary-codeddecimal data from up to six instruments into computercompatible code on punched tape, magnetic tape, or punched cards. 


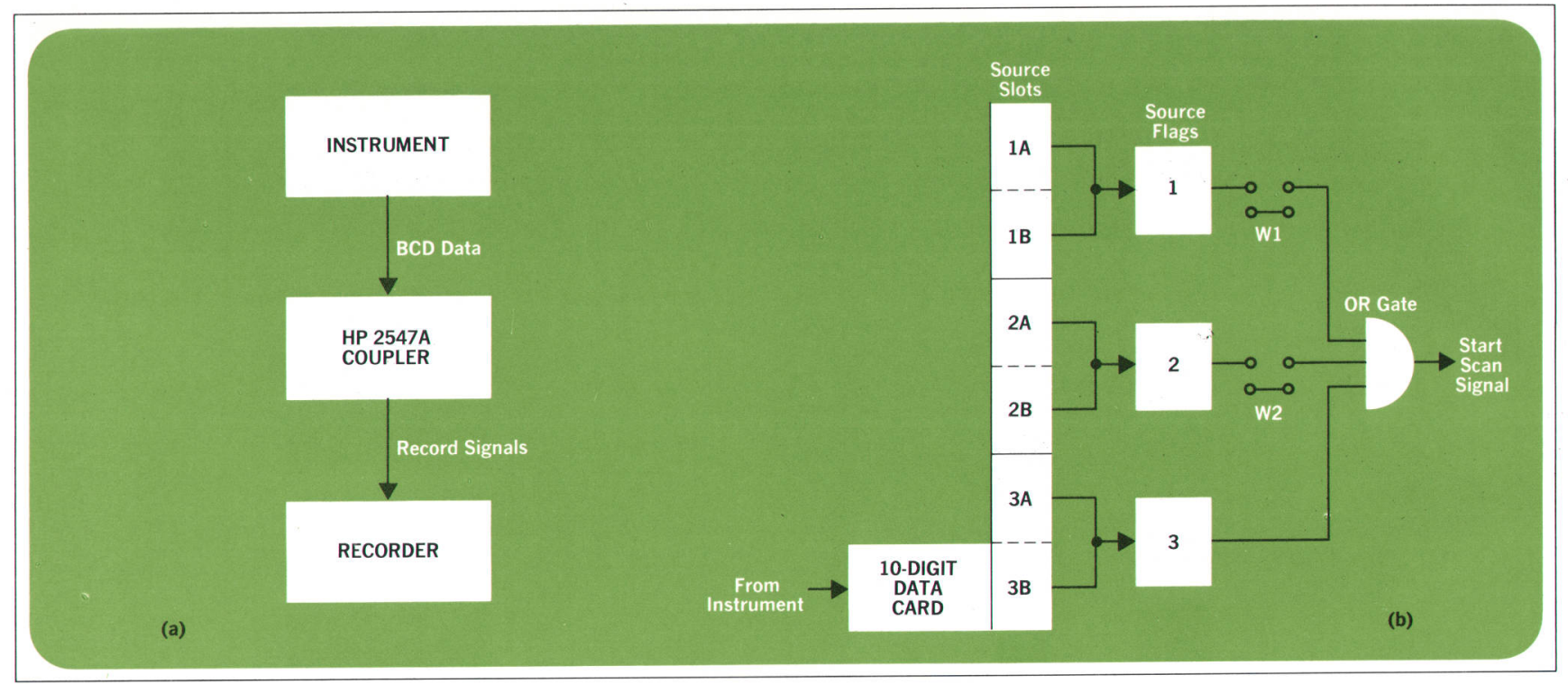

Fig. 2. Instruments are connected by cables to 10-digit data cards which plug into the Model 2547A Coupler. When a start-scan signal occurs, the coupler scans sources 1 , 2 , and 3 in order, and records data from any source whose flag is set.

Spaces can be inserted to make printed copies of the data more legible. In simple data logging applications, in which the record is a typewritten page, measurements from different instruments can be typed in different columns, or the data can be arranged in blocks.

An optional modification of the coupler formats the data in the BASIC programming language, ${ }^{[1]}$ which is used in many time-sharing systems. The coupler automatically prefaces the data by statement numbers and the word 'DATA' so the recorded data can be entered directly into data reduction programs written in BASIC. This use of the coupler will be discussed in more detail later in this article. Alternatively, records may be formatted without the word 'DATA' for storage in BASIC or FORTRAN time-share files.

\section{Expandable Input}

The coupler's basic input capacity is 10 digits. This can be expanded to accommodate as many as six separate instruments, each having 10-digit output. The instruments are grouped in pairs; when both instruments of any pair send record commands to the coupler, the coupler scans the three pairs in a fixed order and records data from any pair that is ready. Since the order of the scan is fixed, the relative priority of the instruments is determined by the order in which their printed-circuit cards are placed in the coupler's card slots. (The slots are behind the front panel.)

When time is needed as part of the recorded data, an optional digital clock can be added to the coupler. An- other option is manual data entry, which can be used to add up to 12 digits of manually-set data to the digital record for listing such things as run numbers and dates.

Besides its use with separate instruments, the coupler can also be used to record both measurement data and channel identification information in data acquisition systems which employ a digital voltmeter and an input scanner. With the optional clock, the coupler can periodically trigger the scanner to begin a new scan.

\section{Set It and Forget It}

The new coupler has been designed to let systems control rest in the instruments or scanner connected to it. After initial setup, the coupler requires no further attention. The instruments operate normally, while the coupler simply records the data they present. Since the coupler's controls are seldom used, they are located behind the swing-out front panel. Only the optional manual-data thumbswitches and the optional clock display are located on the front panel.

Because it is designed as a system component, the coupler has other uses besides its basic one of automating laboratory data recording. For example, manufacturers of systems which include recording devices may find the coupler an attractive alternative to a specially designed interface between their data sources and their recorder.

\section{How It's Used}

The best way to see what the coupler can do is to consider a number of examples of its use. The examples 


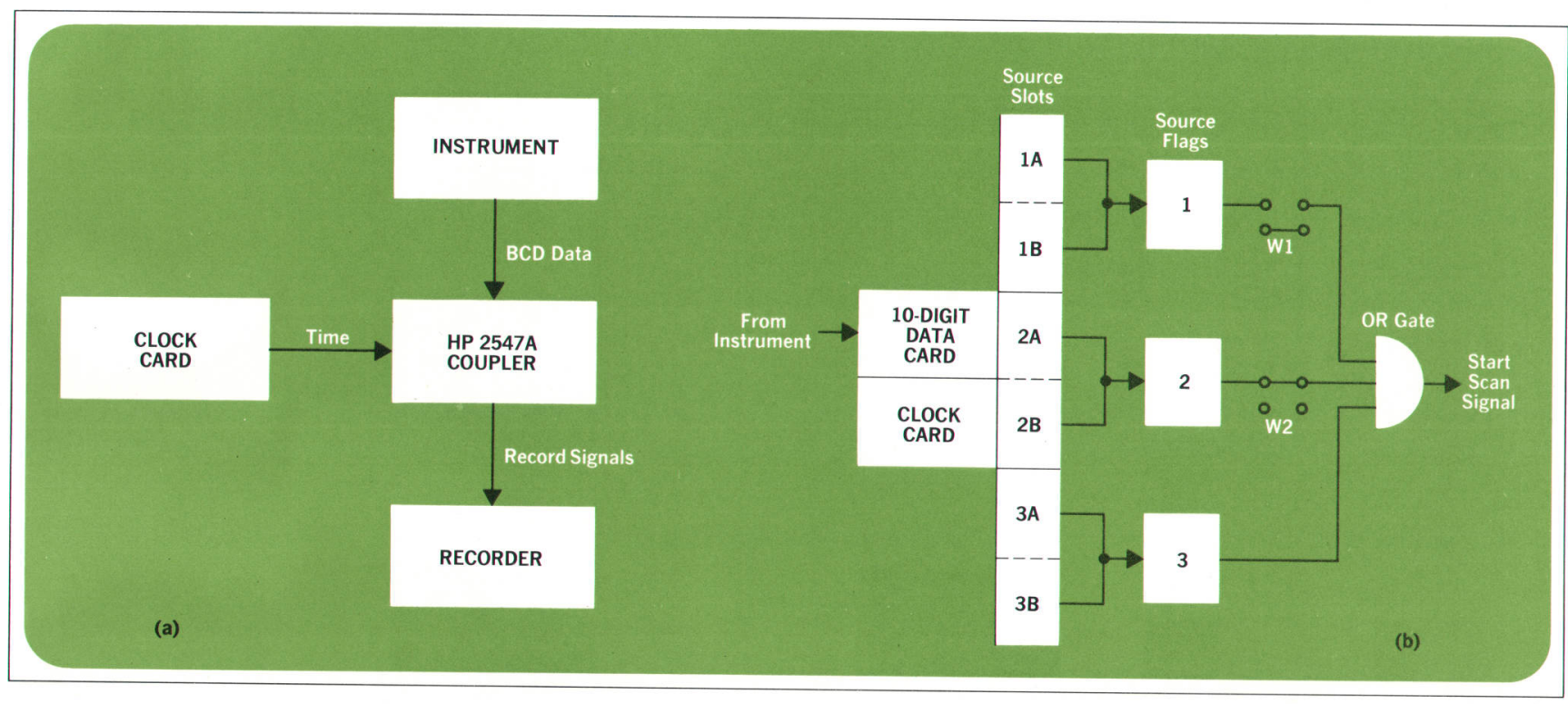

Fig. 3. An optional six-digit clock can be used to record the time of day along with instrument readings.

that follow are representative, but not exhaustive. ${ }^{[2]}$

Single Instrument. Suppose that data from a single instrument such as a counter or a digital voltmeter are to be recorded, as shown in Fig. 2(a). Fig 2(b) shows how the coupler's input section would be arranged. A standard cable connects the instrument to a 10-digit data card, which can be placed in any of the six input slots. In Fig. 2(b), the card is in the slot corresponding to source $3 \mathrm{~B}$. The two jumpers on the control card, W1 and W2, are positioned as shown, since sources 1 and 2 are not used.

Measurements can be initiated manually by pressing the instrument's reset button, or the instrument can be set to make repeated measurements at the rate determined by its sample rate control. When each measurement is completed, the instrument sends a record command to the coupler, causing the digital data to be transferred in parallel to the storage registers of the data card. During the transfer, the data card sends a holdoff signal to the instrument to inhibit further measurements. The transfer takes less than 1.5 milliseconds. * After it is completed, the instrument is free to measure again.

Transfer of the data also sets a source flag, number 3 in this case, which in turn generates a start scan signal. This tells the coupler to look for and record the data. The coupler scans sources 1, 2, and 3 in order. When it finds the source which set the flag, the data in the data card are transferred to the coupler's formatter, where the char-

* The transfer takes place after a delay which allows the data signals time to settle. The delay is adjustable from $100 \mu \mathrm{s}$ to $1.5 \mathrm{~ms}$. The delay required will depend upon the actual settling time, which is a function of the output impedance of the instrument and the cabling capacity. acters are arranged in the desired order, then translated serially to the desired recording code and recorded.

Multiple Instruments. The coupler has three source inputs, each of which can accommodate two 10-digit input cards. Therefore up to six instruments can be served by the coupler. Each instrument would be connected by cable to a 10-digit input card in the coupler, and the positions of jumpers W1 and W2 would depend upon which sources were to be permitted to initiate a scan.

When two instruments are connected to the same source input, the first instrument to issue a record command is held off until the second issues a record command. Then the flag for that source is set and the data are formatted, serialized, and recorded in one word which may be up to 20 digits long. Data from all three sources are recorded in the same format which, of course, is selectable.

Normally, all of the instruments must have the same BCD output code, although the logic levels may be different. An optional version of the coupler will accept one $\mathrm{BCD}$ code from one source and a different BCD code from the other two.

If record commands from the instruments don't always occur in the same sequence, source identification can be provided by installing optional input cables which have a source identification digit wired in at one of the ten character locations.

Recording Time with Measured Data. Frequently in the measurement of time-varying quantities it is important that the time and the measured data be recorded to- 
gether. The coupler has a clock option which can record the exact time of day with each measurement. The clock option includes a clock input card, a time-interval output card, and a digital front-panel display. Fig. 3 illustrates the use of the clock card for recording the time of day along with the data from a single instrument. The clock card can be located in source input $1 \mathrm{~B}$ or $2 \mathrm{~B}$, and the instrument's data card should occupy the adjacent source location (1A or $2 \mathrm{~A}$ ). Because both cards are in the same source input, the instrument must have the same BCD code as the clock $(+8421)$.

No record commands are issued by the clock. When the instrument issues a record command, the corresponding source flag is set and the coupler begins its scan. When it finds the set flag, the coupler records the instrument's data and the time of day in the same word.

Two Instruments With Clock and Timed Control. For experimental setups which call for periodic measurements, the coupler's time-interval output card (part of the clock option) can be used to trigger the instrument readings. The time-interval card has two independent outputs. In Fig. 4(a), a counter and a digital voltmeter are being independently triggered to take readings at two different preset intervals. The intervals can be $1 \mathrm{~s}, 10 \mathrm{~s}, 1 \mathrm{~m}, 10 \mathrm{~m}$, or $1 \mathrm{~h}$, or an integer multiple (1 to 9 ) of these. When two instruments are taking readings at different rates, their cards should be placed in different source inputs, as shown in Fig. 4(b), so that each instrument can have random access to the coupler and the recorder.

An option can be provided to preface each instrument's recording with the time of day. With this option, the setting of either the source 2 flag or the source 3 flag simultaneously sets the source 1 flag. Since the coupler always scans the sources in order, the clock data from source $1 \mathrm{~B}$ will be recorded first, followed by the instrument data from source $2 \mathrm{~B}$ or $3 \mathrm{~B}$.

Source identification may be provided either as described in 'Multiple Instruments,' above, or by means of the optional manual-data cards as shown in Fig. 4(b). When the manual-data cards are installed, front-panel thumbwheel switches can be set to record data in the source locations corresponding to the card positions (2A and $3 \mathrm{~A}$ in this case). In Fig. 4(b) one digit of manual data is being formatted from sources 2 and 3 to identify which instrument took which data. Like the clock, the manual-data cards require that instruments sharing their source locations have the same BCD output code $(+8421)$.

Data Acquisition System. When many measurements at different points have to be taken, an analog input scanner and a digital voltmeter can be combined with the Model 2547A Coupler to make a data acquisition system as shown in Fig. 5(a). Dc voltage, ac voltage, resistance, and frequency can all be measured directly by many dig-

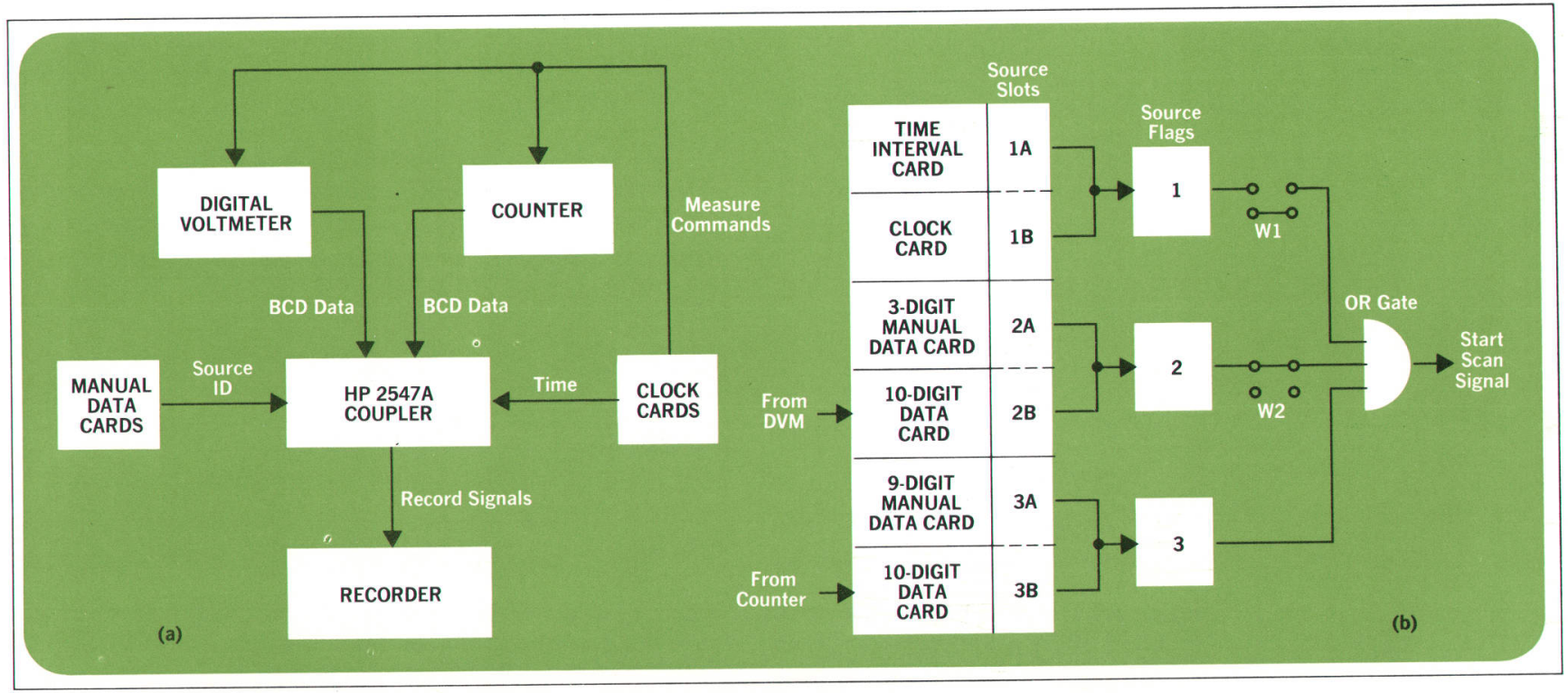

Fig. 4. Part of the clock option is a time-interval card which can command instruments to take readings at preset intervals. The card has two independent outputs so that different instruments (the counter and the DVM in this case) can take readings at different intervals. The manual-data cards are being used here to identify the source of each data word. 
ital voltmeters, and virtually any physical quantity can be converted into an electrical equivalent by an appropriate transducer.

For computer analysis, each measurement must have a channel identification number recorded with it so the computer will know where the data originated. To enter this information, a channel-ID card is used in the coupler. It is placed in the source input location adjacent to the voltmeter data card. In Fig 5(b), it is in source 3A. The channel-ID card receives a three-digit channel number from the scanner and causes it to be recorded along with the voltmeter readings.

Each time the coupler records a reading it sends a channel-advance signal to the scanner. When the next channel has been accessed, the scanner commands the voltmeter to measure. The voltmeter then measures and issues a record command to the coupler. This process continues until the end of the scan is reached.

To permit the system to operate unattended over long periods of time, the clock option can be used to trigger a new scan at preset intervals. A jumper on the channelID card can be set to record the time of day before the first measurement of each scan.

Often it is useful to identify a record with run number, date, and other information. This information can be inserted manually into the record at any time by means of the manual-data option. The manual-data cards are placed as shown in Fig. 5(b). The data are set on the 12 front-panel thumbswitches and recorded by pushing a button. Manual data can also be entered automatically at the beginning of each scan by setting a jumper on the channel-ID card.

\section{BASIC Formatting}

When data are to be recorded for processing through time-share terminals using the BASIC language, the exact coupler configuration will depend upon the particular application. The situation illustrated in Fig. 6 is fairly typical. A counter and a digital voltmeter are being used to test a discriminator circuit, and the coupler is formatting the data as follows for use as part of a BASIC program which determines the discriminator's linearity.

$\begin{array}{llll}\phi \phi \phi 1 & \text { DATA } & 3947476,289321 \\ \phi \phi \phi 2 & \text { DATA } & 2847941,26945 \phi \\ \phi \phi \phi 3 & \text { DATA } & 24843 \phi 5,1967 \phi 3\end{array}$

Each line has a line number followed by the word 'DATA', the input frequency of the discriminator being tested, and its output voltage. The initial line number may be set to any desired value. The coupler's input configuration is as shown in Fig. 6(b), and the coupler's patchboard formatter is arranged so the counter's reading is recorded first in each line. A modified clock card

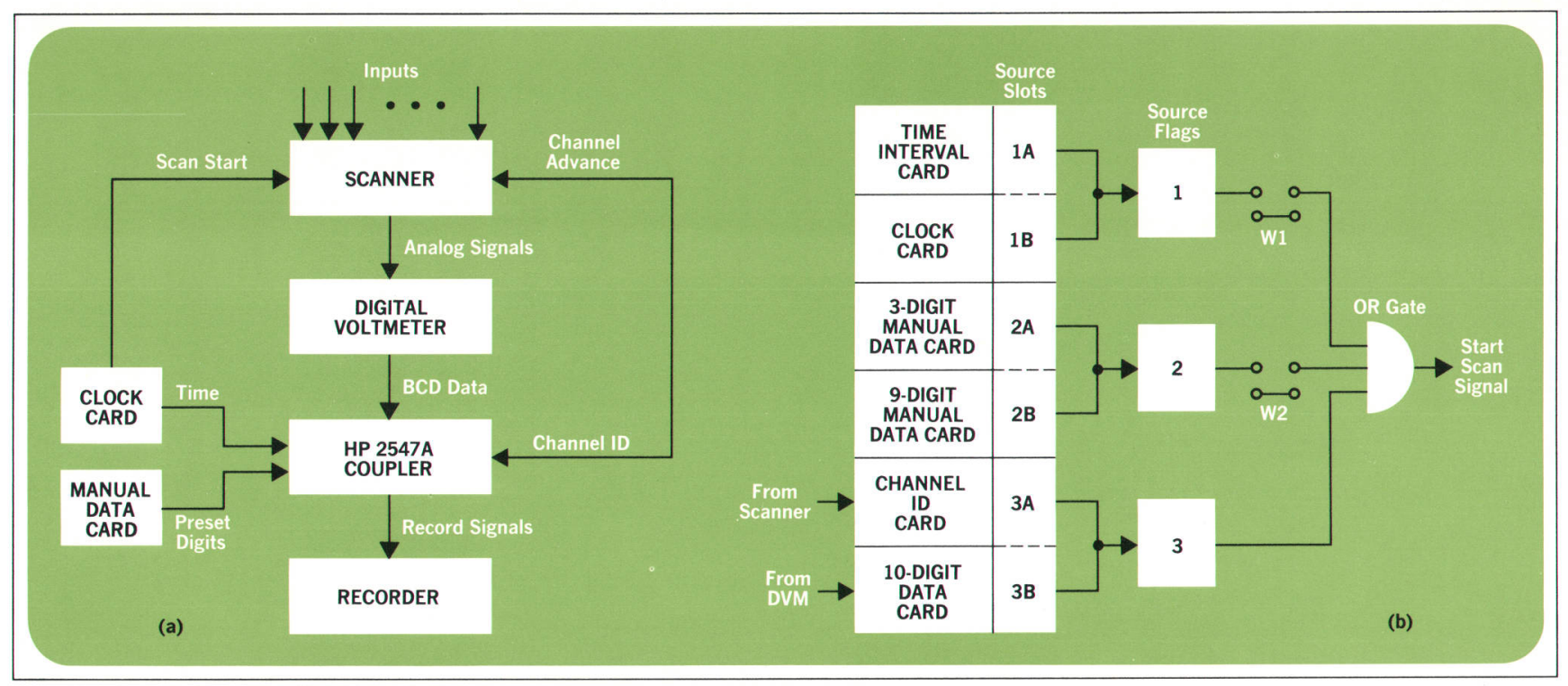

Fig. 5. A Model 2547A Coupler, a scanner, and a digital voltmeter form a data acquisition system. The channel-ID card adds channel numbers to the data. The manualdata cards are being used to insert the date and run number at the beginning of the record. The clock records the time of day at the beginning of each scan. 


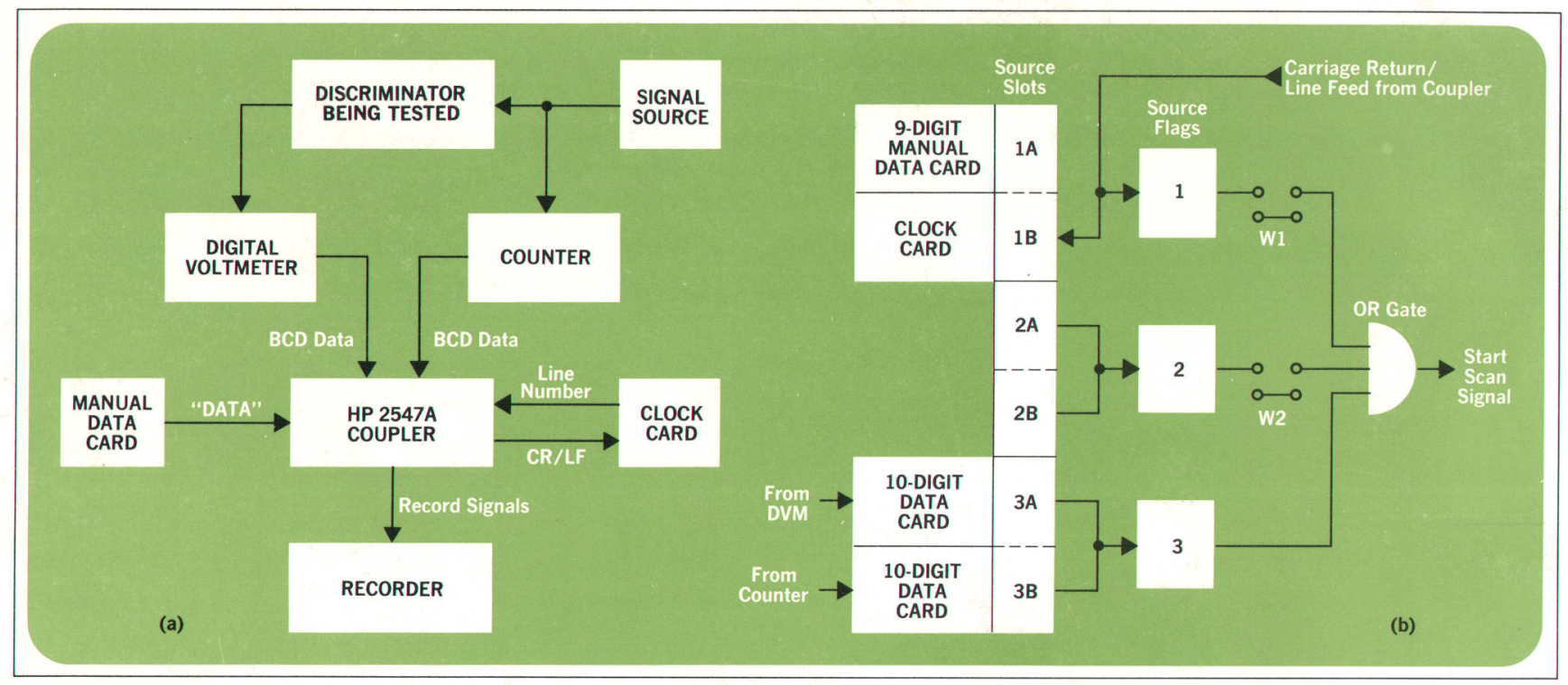

Fig. 6. When data are being formatted for processing by BASIC-language time-sharing terminals, a modified clock card acting as a counter generates line numbers, and a manual-data card inserts the word 'DATA' after each line number. Data can also be formatted to be stored directly in BASIC or FORTRAN files.

functions as a counter to generate line numbers; it starts at any present number and advances one count for each line. The coupler is set to generate the carriage-return/ line-feed signals after recording the data from source 3; these same signals are used to set source flag 1 so the line number will enter first when the next measurement initiates another recording cycle. A hard-wired manualdata card puts the word 'DATA' into the record, and the comma is produced by hard-wiring an unused digit in the DVM's output cable.

\section{Acknowledgments}

As with any project, many people have contributed their ideas and effort. To only name a few, industrial design was by Paul G. Priestley; Bruce Harvey was the product designer; Gilbert P. Seymour smoothed the way into manufacturing; Nino Mateos contributed marketing ideas; Lester Moore did the testing and lent all-around technical support; Donald C. Loughry contributed support and counsel.

\section{References}

[1] G. L. Peterson, 'BASIC - The Language of Time Sharing,' Hewlett-Packard Journal, November 1968.

[2] 'Recording Digital Measurements with the HP 2547A Coupler,' Hewlett-Packard Application Note 113.

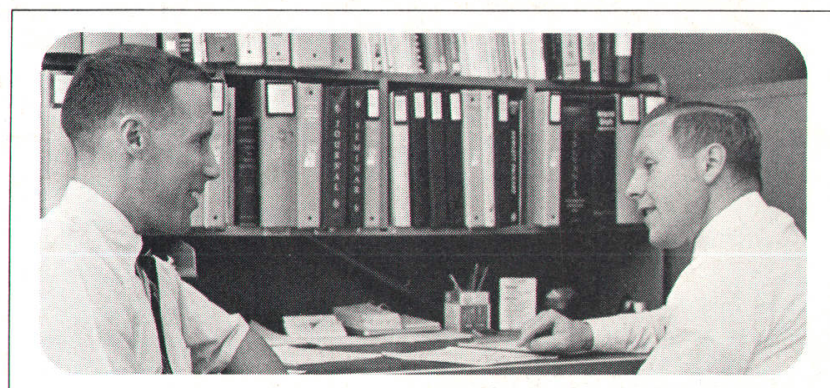

Robert L. Knapp (right) is manager of data systems development for HP's Palo Alto Division. He was project manager for the 2547A Coupler. Bob received his B.S. in electrical engineering from San Diego State College in 1950. He joined HP in 1956, and has been project engineer for many special systems and for three data acquisition systems. He is a member of IEEE and a senior member of ISA.

William J. Steinmetz (left) graduated from Duke University in 1959 with a B.S. in electrical engineering. He received his MSEE from the University of New Mexico in 1963 and has done additional graduate work in electrical engineering at MIT and in business at the Harvard Business School. Before joining HP in 1966, Bill worked on the design of digital instrumentation systems and served as a project officer for the Air Force. At HP Bill has done applications engineering for the Palo Alto Division. He is currently product manager for data acquisition systems. Bill is a member of IEEE and Eta Kappa Nu. In his spare time he enjoys mountain climbing, tennis and skiing.

\section{HEWLETT-PACKARD JOURNAL JANUARY 1969 Volume $20 \cdot$ Number 5}

TECHNICAL INFORMATION FROM THE LABORATORIES OF THE HEWLETT-PACKARD COMPANY PUBLISHED AT 1501 PAGE MILL ROAD, PALO ALTO, CALIFORNIA 94304 Editorial Staff: F. J. BURKHARD, R. P. DOLAN, L. D. SHERGALIS, R. H. SNYDER Art Director: R. A. ERICKSON 


\section{HP Archive}

This vintage Hewlett-Packard document was preserved and distributed by

www.hparchive.com

Please visit us on the web!

On-line curator: John Miles, KE5FX jmiles@pop.net 
